This item was submitted to Loughborough's Research Repository by the author.

Items in Figshare are protected by copyright, with all rights reserved, unless otherwise indicated.

\title{
Augmented biohydrogen production from rice mill wastewater through nano- metal oxides assisted dark fermentation
}

PLEASE CITE THE PUBLISHED VERSION

https://doi.org/10.1016/j.biortech.2020.124243

PUBLISHER

Elsevier

VERSION

AM (Accepted Manuscript)

\section{PUBLISHER STATEMENT}

This paper was accepted for publication in the journal Bioresource Technology and the definitive published version is available at https://doi.org/10.1016/j.biortech.2020.124243

\section{LICENCE}

CC BY-NC-ND 4.0

\section{REPOSITORY RECORD}

Rambabu, K, G Bharath, A Thanigaivelan, Diganta Das, PL Show, and F Banat. 2020. "Augmented Biohydrogen Production from Rice Mill Wastewater Through Nano-metal Oxides Assisted Dark Fermentation”. Loughborough University. https://hdl.handle.net/2134/13176587.v1. 


\section{Augmented biohydrogen production from rice mill wastewater through}

2 nano-metal oxides assisted dark fermentation

3 K Rambabu ${ }^{1}$, G Bharath ${ }^{1}$, A Thanigaivelan ${ }^{1}$, DB Das ${ }^{2}$, Pau Loke Show ${ }^{3, *}$, Fawzi Banat ${ }^{1}$

$4{ }^{1}$ Department of Chemical Engineering, Khalifa University, P.O. Box 127788, Abu Dhabi,

5 United Arab Emirates

$6{ }^{2}$ Department of Chemical Engineering, Loughborough University, Loughborough LE11 3TU,

7 Leicestershire, UK

$8{ }^{3}$ Department of Chemical Engineering, Faculty of Science and Engineering, University of

9 Nottingham Malaysia, 43500 Selangor Darul Ehsan, Malaysia.

10

11

12

* Corresponding author:

Prof. Pau Loke Show

Department of Chemical and Environmental Engineering

Faculty of Science and Engineering

University of Nottingham Malaysia

Jalan Broga, 43500 Semenyih

Selangor Darul Ehsan, MALAYSIA

Email: PauLoke.Show@nottingham.edu.my; showpauloke@gmail.com 


\section{ABSTRACT}

This study highlights biohydrogen production enrichment through $\mathrm{NiO}$ and $\mathrm{CoO}$ nanoparticles (NPs) inclusion to dark fermentation of rice mill wastewater using Clostridium beijerinckii DSM 791. NiO ( 26 nm) and CoO ( 50 nm) NPs were intrinsically prepared via facile hydrothermal method with polyhedral morphology and high purity. Dosage dependency studies revealed the maximum biohydrogen production characteristics for $1.5 \mathrm{mg} / \mathrm{L}$ concentration of both NPs. Biohydrogen yield was improved by 2.09 and 1.9 folds higher for optimum dosage of $\mathrm{NiO}$ and $\mathrm{CoO}$ respectively, compared to control run without NPs. Cometabolites analysis confirmed the biohydrogen production through acetate and butyrate pathways. Maximum COD reduction efficiencies of $77.6 \%$ and $69.5 \%$ were observed for $\mathrm{NiO}$ and $\mathrm{CoO}$ inclusions respectively, which were higher than control run (57.5\%). Gompertz kinetic model fitted well with experimental data of NPs assisted fermentation. Thus, NiO and $\mathrm{CoO}$ inclusions to wastewater fermentation seems to be a promising technique for augmented biohydrogen production.

Keywords: Biohydrogen; $\mathrm{NiO}$ nanoparticles; $\mathrm{CoO}$ nanoparticles; $\mathrm{COD}$ reduction efficiency; Rice mill wastewater; Clostridium beijerinckii.

2 


\section{Introduction}

The rapid depletion of fossil fuel deposits and the adverse environmental effects caused by the greenhouse gases released during these fuels combustion, have triggered the search for alternate renewable energy sources (Engliman et al., 2017). Hydrogen gas has been regarded as an ideal substitute for these fossil fuels due to its salient merits of highest gravimetric energy density $(\sim 120 \mathrm{~kJ} / \mathrm{g})$, production of zero carbon emissions upon combustion and the higher energy carrying efficiency (Rambabu et al., 2019). Hydrogen could be produced through various physicochemical methods. However these techniques, specifically methods like coal gasification and steam reforming technologies, require extreme pressure and temperature operation conditions making them energy intensive and quite expensive (Kumar et al., 2019). Hence, attempts on economic mode of clean and efficient production of hydrogen has gained huge interest and attention among researchers. Thus, the synthesis of hydrogen by biological means serve the purpose and provide an essential bridge between the renewable energy sources and sustainable energy resources (Lin et al., 2016).

Lignocellulosic substances have been the conventional and efficient substrates used for biohydrogen production. However, recent decades have witnessed the biohydrogen production from industrial effluents also. These organic wastes when discharged into the environment is one of the most serious causes for water pollution and aquatic eco-system damage. Hence, emphasis on biohydrogen production from these organic effluents is a promising approach to evade their pollution effects and provide a suitable alternative for their reusage (Gadhe et al., 2015a; Ramprakash and Muthukumar, 2014). Moreover, unlike the lignocellulosic substrates, these organic effluents do not cause a threat to food security and, hence, they are considered as viable and costless biohydrogen sources, particularly in developing and under developed countries which suffer from limited energy resources.

Rice mill waste water (RMWW) is one of the productive and renewable biosource for hydrogen production due to its higher biodegradable organic content (Ramprakash and Muthukumar, 2014). In general, rice production steps involve soaking of paddy in water, steaming to kill the microbes, and drying to eliminate the moisture content. This is followed by milling processes that involves dehusking, paddy separation, polishing and grading to produce edible rice product (Pan et al., 2019). The amount of wastewater produced for this entire operation is about 1.0 to $1.2 \mathrm{~L} / \mathrm{kg}$ paddy. RMWW is a rich source of starch, celluloses and hemicelluloses which can be readily hydrolysed by microbes (Ramprakash and Muthukumar, 2014). Furthermore, this waste water stream is characterized to possess a higher 
chemical oxygen demand (COD) and hence suitable for anaerobic fermentation (Choudhary et al., 2015; Ramprakash and Muthukumar, 2014).

Clostridium beijerinckii, a gram-positive, sporulating thermophilic-anaerobic bacterium is the most widely used microbe for hydrogen production. The genome analysis of this bacterium has proved the presence of genes encoding for the electron carriers and enzymes that assists hydrogen production (Fonseca et al., 2019). In general, there are two metabolic pathways for the production of hydrogen by glucose fermentation namely, the formate hydrogen production pathway that involves formate hydrogen lyase and the reduced nicotinamide adenine dinucleotide (NADH)-dependent hydrogen production pathway that requires hydrogenases (Kumar et al., 2019). Both formate hydrogen lyase and hydrogenase enzymes are present in Clostridium beijerinckii which makes it a versatile organism for fermentative biohydrogen production (Trchounian et al., 2017). Further, this thermophilic microbe enhances the sugar conversion and hydrogen production rate at higher temperatures as these operational conditions are energetically more favourable for biohydrogen production (Kumar et al., 2019; Trchounian et al., 2017). The higher temperature also minimizes an occurrence of undesirable metabolic side reactions and restricts the contamination by hydrogenotrophic methanogens (Leong et al., 2019). These factors have made Clostridium beijerinckii as an ideal organism for consolidated bioprocessing of hydrogen production (Kumar et al., 2019; Pawar and Van Niel, 2013; Singer et al., 2018).

In spite of these added advantages, this thermophile bacteria suffer a drawback of low volumetric productivity (Desvaux, 2006). Augmentation of hydrogen production enzymes in the microbial metabolic pathway by the inclusion of metal oxide nanoparticles is one of the effective strategies adopted to overcome this limitation (Kumar et al., 2019). Hydrogenase is an enzyme that catalyses the bioreduction of protons into hydrogen. Nickel (Ni) is present in the core active site of [Ni-Fe] hydrogenase and, hence, the addition of nickel at optimal concentrations into the fermentation medium has proven to increase the biohydrogen productivity (Gadhe et al., 2015a; Mishra et al., 2018). Similarly, cobalt based metallic modifiers have also demonstrated their enhancement role in biohydrogen production through microbial reactions (Mishra et al., 2018). Cobalt (Co) is mainly found in the corrin ring of coenzyme $\mathrm{B}_{12}$ related enzymes, a cofactor involved in methyl group transfer and in rearrangement reactions. Enzymes containing Co components play a vital role in the metabolic processes of bacterial cell, specifically for biohydrogen synthesis (Rodionov et al., 2006). Hence supplementing this metal ion to fermentation medium enhances the cell proliferation and the resultant biohydrogen and co-metabolites production. It is also observed that Co ions 
regulate the $\mathrm{pH}$ of fermentation medium in a favourable manner, thus promoting the metabolic pathway towards higher hydrogen production (Mishra et al., 2018; Qiang et al., 2012).

Notably, when these $\mathrm{Ni}$ and Co based metal ions are added into the fermentation medium in their oxide forms, there is a decrease in the fermentation medium's toxicity levels and assistance in the retention of microbial cells viability. Further, inclusion of these metal oxides in nano form enhances the biohydrogen productivity in a significant manner than their bulk form additions. This is mainly due to the higher specific surface areas and quantum size effects which increase the adsorbance of the electrons which helps in efficient electron exchange between these nanoparticles (NPs) and hydrogenase (Kumar et al., 2019). The higher specificity of the NPs directly targets the hydrogenase and increase the electron transfer efficiency in anaerobic microorganism. Further, these metal oxide NPs act as an extracellular appendages (bacterial nanowires) for the electron transfer between adjacent cells (Zhang et al., 2018).

Considering all these reported facts, this reported work examined the impact of $\mathrm{NiO}$ and $\mathrm{CoO}$ NPs inclusion on the biohydrogen production from RMWW using Clostridium beijerinckii DSM 791 by dark fermentation. The metal oxide NPs were prepared intrinsically using a facile hydrothermal process and were characterized systematically. Dosage effects of these NPs on the yield of biohydrogen and co-metabolites were investigated to identify their optimal concentration for hydrogen productivity. Further, the kinetic analysis of the anaerobic biological hydrogen productivity was studied using Gompertz and modified Logistic function models. Comparison on the biohydrogen yield obtained through this work with other reported researches are presented and discussed.

\section{Materials and methods}

\subsection{Substrate and pretreatment}

Rice mill wastewater (RMWW) was acquired from a medium-scale rice-processing mill situated in Cuddalore, Tamilnadu, India. Following a $2 \mathrm{~h}$ settling time, the supernatant water was filtered through a 100 mesh (US standard $\sim 0.149 \mathrm{~mm}$ sieve opening) to remove all fine and coarse solid aggregates present in the RMWW. The filtered water was then sterilized for $15 \mathrm{~min}$ at $121^{\circ} \mathrm{C}$ and $15 \mathrm{psi}$ to eliminate any indigenous microbes present in the waste water. Consequently, a definite volume of $1.5 \%(\mathrm{v} / \mathrm{v})$ sulphuric acid was added to the RMWW feed, followed with a high pressure heating at $15 \mathrm{psi}$ and $121^{\circ} \mathrm{C}$ for $1 \mathrm{~h}$. The acid pre-treated RMWW feed was then cooled and stored at $4{ }^{\circ} \mathrm{C}$ (in order to prevent the biological degradation) until further use. The salient physicochemical characteristics of the pre-treated RMWW are as 
follows: pH 6.3, BOD 9,600mg/L, COD 19,800 mg/L, Volatile suspended solids 11,200 g/L, Total dissolved solids 8,500 mg/L, Total solids 13,900 mg/L, Total nitrogen $3.9 \pm 0.25 \mathrm{~g} / \mathrm{L}$, Acetate $1.36 \pm 0.31 \mathrm{~g} / \mathrm{L}$ and Butyrate $2.69 \pm 0.19 \mathrm{~g} / \mathrm{L}$.

\subsection{Microorganism and inoculum preparation}

Clostridium beijerinckii DSM 791 was procured from the Leibniz-Institut DSMZ, Germany and pre-cultured using the reinforced clostridial medium (Skonieczny and Yargeau, 2009). The medium $\mathrm{pH}$ was adjusted to 6.8 (using $0.1 \mathrm{~N} \mathrm{NaOH}$ or $0.1 \mathrm{~N} \mathrm{H}_{3} \mathrm{PO}_{4}$ buffer solutions) and then subjected to $48 \mathrm{~h}$ incubation at $37^{\circ} \mathrm{C}$ and $180 \mathrm{rpm}$ in an orbital shakerincubator (CIS-24 Plus, REMI, India). Subsequently, the culture media was stored in serum bottles under anaerobic conditions after purging the bottles with 100\% nitrogen. All reagents and solutions used in this study were purchased from Merck, Germany. All the chemicals used for the study were of analytical grade and were purchased from Merck, Germany.

\subsection{Synthesis of NiO and CoO NPs}

A facile hydrothermal technique was adopted for the synthesis of the metal oxide NPs according to the procedure described by Jiang et al., 2013 with slight modifications. Nickel (II) nitrate hexahydrate $\left(\mathrm{Ni}\left(\mathrm{NO}_{3}\right)_{2} \cdot 6 \mathrm{H}_{2} \mathrm{O}\right)$ and Cobalt (II) nitrate hexahydrate $\left(\mathrm{Co}\left(\mathrm{NO}_{3}\right)_{2} \cdot 6 \mathrm{H}_{2} \mathrm{O}\right)$ were used as the precursors for the preparation of $\mathrm{NiO}$ and $\mathrm{CoO}$ NPs, respectively. Briefly, about $2.9 \mathrm{~g}$ of the nitrate precursor was dissolved in $30 \mathrm{~mL}$ of deionized water under sonication (S50, Fisherscientific, Norway) for $15 \mathrm{~min}$. To this solution, $5.5 \mathrm{~g}$ of D-glucose was included and magnetically stirred (MS-800 Plus, REMI, India) for $30 \mathrm{~min}$. The $\mathrm{pH}$ of the mixture was then adjusted to 9 through drop-wise addition of $2 \mathrm{M}$ urea solution. Subsequently, this solution mixture was transferred to $100 \mathrm{~mL}$ teflon-lined hydrothermal steel container (TechInstro, India) and heated for $6 \mathrm{~h}$ at $180^{\circ} \mathrm{C}$ in a hot air oven. The solid precipitate was then filtered, washed thoroughly with deionized water and ethanol, and vacuum dried (Vacutherm, ThermoFisher, Germany) for $3 \mathrm{~h}$ at $70{ }^{\circ} \mathrm{C}$. A final calcination of the metal oxide-carbon composite was done in a muffle furnace (TLPPL 115, Technico, India) for $3 \mathrm{~h}$ at $550{ }^{\circ} \mathrm{C}$ (using a ramp rate of $5{ }^{\circ} \mathrm{C} / \mathrm{min}$ ) to eliminate the carbon portion. The obtained metal oxide NPs were then powdered and stored in air-tight vials for further characterizations and experiments.

\subsection{Characterization of $\mathrm{NiO}$ and $\mathrm{CoO}$ NPs}


Morphology and elemental composition of the as-prepared metal oxides were examined using scanning electron microscope (FEG Quanta-250, USA), equipped with energy dispersive $\mathrm{X}$-Ray analyser. Structural characteristics of the NPs samples were investigated through an Xray diffractometer (D-8, Bruker, Germany) at $40 \mathrm{kV}$ and $40 \mathrm{~mA}$ in the $2 \theta$ range of $10^{\circ}-70^{\circ}$. Particle size distributions of the NiO and $\mathrm{CoO}$ NPs were studied using a dynamic light scattering equipment (SZ-100V2, Horiba, Japan). The mean particle size of the metal oxides was evaluated using the Z-average methodology.

\subsection{Biohydrogen synthesis by batch fermentation}

Batch experiments for anaerobic mode of dark fermentation were performed in $100 \mathrm{~mL}$ serum bottles. A volume of $50 \mathrm{~mL}$ of acid pre-treated RMWW and 10\% freshly prepared inoculum were introduced into the bottles (Ramprakash and Muthukumar, 2014). The effect of a given metal oxide NPs on biohydrogen production was studied by indigenous addition of the NPs at varying concentrations to individual serum bottles containing the fermentation media. The dosage dependency effects of the NPs were studied for six different concentrations $(0.5$, 1.0, 1.5, 2.0, 2.5 and $3.0 \mathrm{mg} / \mathrm{L}$ ). The fermentation medium without the NPs was used as a control. The initial $\mathrm{pH}$ of the medium was adjusted to 7.0 by $0.1 \mathrm{~N} \mathrm{NaOH}$ or $0.1 \mathrm{~N} \mathrm{H}_{3} \mathrm{PO}_{4}$ buffers. The system was then incubated at $37^{\circ} \mathrm{C}$ and $180 \mathrm{rpm}$ for an overall fermentation period of $72 \mathrm{~h}$. Anaerobic conditions were maintained through nitrogen gas purging to the fermentation system. Sample analysis of the medium and the obtained product gas were performed at $12 \mathrm{~h}$ frequency. To ensure the value consistency, the experiments were repeated three times and the results are presented with necessary error bands.

\subsection{Analytical methods}

\subsubsection{Biohydrogen and co-metabolites estimation}

Gas-chromatography system fitted with thermal-conductivity detector (GC-2014, Shimadzu, Japan) was used to evaluate the biohydrogen yield obtained from the RMWW fermentation. Shin carbon (50/80 mesh) stuffed stainless column $(0.2 \mathrm{~m} \times 3 \mathrm{~mm}$ diameter $)$ was employed for the gas analysis. Measurements were performed using Helium carrier gas at a flowrate of $30 \mathrm{~mL} / \mathrm{min}$. The major co-metabolites of the fermentation process, namely ethanol, acetates and butyrates were estimated using a refractive index (RI) detector facilitated high performance liquid chromatography (Millford, LA, USA). Cation-H cartridge micro-guard and Aminex HPX-87H columns were utilized to analyse the co-metabolites using $0.005 \mathrm{M}$ sulphuric acid as the mobile-phase at a flowrate of $0.5 \mathrm{~mL} / \mathrm{min}$. The liquid samples acquired 
from the fermentation medium were centrifuged (EBA280, Hettich, Germany) for 6 min at $4000 \mathrm{rpm}$ and the supernatant was subjected for the analysis of co-metabolites.

Physicochemical characteristics such as chemical oxygen demand (COD), biological oxygen demand (BOD), total nitrogen (TN), volatile suspended solids (VSS), total dissolved solids (TDS) and total solids (TS), for the RMWW were measured according to the APHA standard methods (American Public Health Association et al., 2005). A digital pH system (HQ411D, Hach, Germany) was utilized to estimate the $\mathrm{pH}$ of the substrate. COD reduction efficiency (\%) for the NPs assisted fermentation system was calculated according to Eq. (1).

$$
C O D \text { reduction efficiency }=\frac{C O D_{\text {initial }}-C O D_{\text {final }}}{C O D_{\text {initial }}} \times 100
$$

where $C O D_{\text {initial }}(\mathrm{mg} / \mathrm{L})$ and $C O D_{\text {final }}(\mathrm{mg} / \mathrm{L})$ are the measured COD values of the feed and digestate.

\subsubsection{Biomass estimation}

Biomass sampling was performed as described in our previous work (Rambabu et al., 2020). Briefly, the sampled cell medium was centrifuged for $6 \mathrm{~min}$ at $4000 \mathrm{rpm}$ to acquire the solid pellet. Subsequent to Phosphate Buffered Saline (PBS) washing, the pellet was alkali treated using $1 \mathrm{~mL}$ of $0.1 \mathrm{M} \mathrm{NaOH}$ and this suspension medium was conditioned for an hour at $4{ }^{\circ} \mathrm{C}$ with frequent vortexing at regular intervals. The alkali treated cells were then subjected to frozen-water bath treatment which involved $-20{ }^{\circ} \mathrm{C}$ conditioning followed with $90{ }^{\circ} \mathrm{C}$ incubation for $15 \mathrm{~min}$. Finally, about $1.2 \mathrm{~mL}$ of this cell volume was included to $1.8 \mathrm{~mL}$ of bicinchoninic acid (BCA) solution and incubated for $15 \mathrm{~min}$ at $37^{\circ} \mathrm{C}$. This was then examined for its absorbance value for an incident wavelength of $562 \mathrm{~nm}$ in a UV-Vis spectrophotometer (U5100, Hitachi, Japan).

\subsection{Kinetic modeling}

Kinetic modeling helps to estimate the kinetic constants of a biochemical reaction which is eventually used in scale-up of the laboratory results to industrial setup. In general, Gompertz and modified Logistic function models are the widely adopted models to study microbial mode of biohydrogen production (Rambabu et al., 2020). These models predict the cumulative hydrogen yield $\left(\mathrm{C}_{Y}\right)$ based on key operational parameters such as fermentation time $(t)$, maximum rate of biohydrogen $\left(M_{R}\right)$, maximum yield of biohydrogen $\left(M_{Y}\right)$ and lag phase period (ג). Origin 8.5 software (Version-8.5, OriginLab, Northampton, USA) was adopted to perform 
the regression fits and to estimate the necessary model parameters. The non-linear exponential forms of the Gompertz and modified Logistic function models are presented in Eqs. (2) and (3).

$C_{Y}=M_{Y} \times \exp \left\{-\exp \left[1+\frac{2.718 \times M_{R}}{M_{Y}}(\lambda-t)\right]\right\}$

$C_{Y}=\frac{M_{Y}}{\exp \left\{\frac{4 M_{R}}{M_{R}}(\lambda-t)+2\right\}+1}$

\section{Results and Discussion}

\subsection{Formation mechanism of the $\mathrm{NiO}$ and $\mathrm{CoO}$ NPs}

A two-step formation mechanism could be postulated for the synthesis of the $\mathrm{NiO}$ and CoO NPs, prepared using the carbonaceous D-glucose as the substrate template (Bharath et al., 2020b). The first step involved the formation of the metal oxide nuclei at the active hydrophilic sites of the D-glucose. The oxygen rich functional sites $\left(\mathrm{OH}^{-}\right.$and $\left.\mathrm{COO}\right)$ of the carbon substrate provided the necessary anchorage for the metal oxide nuclei formation. The various reactions involved with $\mathrm{NiO}$ nuclei formation are presented in Eqs. (4) - (6) while the reactions for $\mathrm{CoO}$ nuclei formation are described through Eqs. (7) - (9)

$$
\mathrm{Ni}\left(\mathrm{NO}_{3}\right)_{2} \rightarrow \mathrm{Ni}^{2+}+2 \mathrm{NO}_{3}^{-}
$$

$\mathrm{Ni}^{2+}+2(\mathrm{OH})^{-} \rightarrow \mathrm{Ni}(\mathrm{OH})_{2, \text { nuclei }}$

$\mathrm{Ni}(\mathrm{OH})_{2, \text { nuclei }} \stackrel{\Delta}{\rightarrow} \mathrm{NiO}_{\text {nuclei }}+\mathrm{H}_{2} \mathrm{O}$

$$
\mathrm{Co}\left(\mathrm{NO}_{3}\right)_{2} \rightarrow \mathrm{Co}^{2+}+2 \mathrm{NO}_{3}^{-}
$$

$\mathrm{Co}^{2+}+2(\mathrm{OH})^{-} \rightarrow \mathrm{Co}(\mathrm{OH})_{2, \text { nuclei }}$

$$
\mathrm{Co}(\mathrm{OH})_{2, \text { nuclei }} \stackrel{\Delta}{\rightarrow} \mathrm{CoO}_{\text {nuclei }}+\mathrm{H}_{2} \mathrm{O}
$$

The second step in the synthesis mechanism comprised of the growth of the metal oxide nuclei through nuclei aggregation and carbon encapsulation which were favoured by the basic $\mathrm{pH}$ environment provided through the urea inclusion (Wu et al., 2016). Finally, the carbon outer shell was decomposed by the calcination step and removed from the NPs core resulting in the formation of fresh $\mathrm{NiO}$ and $\mathrm{CoO} \mathrm{NPs}$.

\subsection{Characterizations of $\mathrm{NiO}$ and $\mathrm{CoO}$ NPs}



composition, structural features and particle size in order to understand their effect on the anaerobic digestion of RMWW using Clostridium beijerinckii. Fig. 1 depicts the results for the scanning electron microscopy (SEM) and energy-dispersive X-ray spectroscopy (EDX) studies for both the NPs. As shown in Figs. 1A and 1C, the synthesized metal oxide particles were in nano scale with a polyhedral morphology. Formation of the NPs with polyhedral shape was due to the non-directional aggregation of the nuclei, especially during the pyrolyzation of the substrate carbon (Bharath et al., 2019). Also, this non-structured morphology of the NPs signified the self-agglomeration effects of the particles through hydrogen bonding, Van der Waals forces and crystal-face attraction (Bharath et al., 2020a). The high surface area associated with the polyhedral structure of the NPs would enhance their electrons conductivity as well as microbial stimulatory effects during the fermentation of RMWW to enhance the resultant biohydrogen production. Further, the chemical compositions of the NPs were confirmed through EDX analysis and the spectra for the same are presented in Figs. 1B and 1D. The results revealed the formation of given NPs with high product purity. Absence of any other element in the NPs product apart from the metal and oxygen atoms, established the effectiveness of the synthesis method towards the production of clean $\mathrm{NiO}$ and $\mathrm{CoO} \mathrm{NPs}$ (Rambabu et al., 2021). Thus, the usage of these pure NPs for the enhancement of biohydrogen production by dark fermentation of RMWW would ensure the desirous excitation effects of the bacteria and their metabolic pathways.

Phase purity and structural nature of the as-synthesized $\mathrm{NiO}$ and $\mathrm{CoO}$ NPs were examined through X-ray diffraction (XRD) studies. Fig. 2A shows the diffractograms obtained for the NiO and $\mathrm{CoO}$ NPs samples. The spectra confirmed that the prepared NPs were completely devoid of the crystallizing carbon substrate. The reflexes felt at $2 \theta$ values of $37.1^{\circ}$, $43.2^{\circ}$ and $62.9^{\circ}$ for the NiO NPs corresponded to the lattice planes of (111), (200) and (220) for the metal oxide. The spectrum acquired for the NiO NPs agreed with the PDF standard 711179 (Zhong et al., 2018). Similarly, the sharp peaks observed at $2 \theta$ values of $19.9^{\circ}, 32.3^{\circ}$, $36.5^{\circ}, 59.2^{\circ}$ and $65.3^{\circ}$ for the $\mathrm{CoO}$ NPs matched with the miller indices of (111), (220), (311), (511) and (440) for the metal oxide. The spectrum obtained for the CoO NPs matched with the PDF standard 48-1719 (Chen et al., 2020). The average crystallite size $(D)$ for the NPs was calculated using Debye-Scherrer equation, $D=0.93 \lambda /(\beta \cos \theta)$, where $\lambda$ is the incident X-ray wavelength $(0.1541 \mathrm{~nm}), \beta$ is full width at half maximum (FWHM) and $\theta$ is the diffraction angle. Based on the Debye-Scherrer equation, the average crystallite size was computed as 21.9 $\mathrm{nm}$ and $53.6 \mathrm{~nm}$ for the NiO NPs and CoO NPs respectively. Additionally, the particle size 
distribution of the metal oxide samples was also evaluated and the results are shown in Fig. 2B. It was evident that particle size of NiO NPs was smaller than the CoO NPs. Based on Zaverage method, the mean particle size was estimated as $26.3 \mathrm{~nm}$ and $50 \mathrm{~nm}$ for the NiO NPs and $\mathrm{CoO}$ NPs, respectively. The results obtained for the particle size distribution matched with the outcomes of the morphology and XRD studies of the NPs. Investigations on the phase purity and particle size of the products confirmed the formation of the pure metal oxide particles in nano dimensions which could easily penetrate into the cell organelles of the microorganism to induce the much needed stimulatory effects towards augmented biohydrogen production.

\subsection{NiO NPs effects on biohydrogen synthesis}

The influence of NiO NPs dosage on anaerobic fermentation of RMWW to produce biohydrogen was examined by differing the NPs concentration in the range of 0.5 to $3 \mathrm{mg} / \mathrm{L}$. Fig. 3A presents the results for the cumulative biohydrogen yield obtained over the complete fermentation period of $72 \mathrm{~h}$. From the results, it was evident that addition of NiO NPs resulted in enhanced biohydrogen yield compared to that of control that was void of the NPs. Hence, it could be concluded that NiO NPs inclusion to fermentation medium had a favourable stimulatory effect on biohydrogen production. For varying dosages of the NPs, an incremental trend was observed for biohydrogen yield up to $1.5 \mathrm{mg} / \mathrm{L}$. A maximum cumulative yield of $214.9 \mathrm{~mL} \mathrm{H} / \mathrm{L}$ was attained at the $1.5 \mathrm{mg} / \mathrm{L}$ of NPs and it was 2.09 folds higher than the fermentation system without the NPs. Highly conductive nature of the NiO NPs enhanced the electron transfers between the participant biomolecules leading to higher yields of the biohydrogen (Mishra et al., 2018). However, the biohydrogen yield showed a decremental trend for NiO NPs dosage $>1.5 \mathrm{mg} / \mathrm{L}$. It was estimated that the hydrogen content in the biogas was decreased by $43.2 \%$ when the NiO NPs concentration was varied from 1.5 to $3.0 \mathrm{mg} / \mathrm{L}$. This is mainly ascribed to the inhibition of hydrogenase production and its associated enzymatic activity for hydrogen production due to excessive levels of the NPs (Tao and Wei, 2004). Thus, a concentration level of $1.5 \mathrm{mg} / \mathrm{L}$ was concluded as the optimal dosage level of $\mathrm{NiO}$ NPs for biohydrogen production. This phenomenon proved that appropriate dosage of $\mathrm{NiO}$ NPs could supply biologically available ions for bacteria via their dissolution into the culture media. Hence, supplementing the microbial medium with suitable dosage of $\mathrm{Ni}$ ions is crucial to direct the $[\mathrm{Ni}-\mathrm{Fe}]$ hydrogenase enzyme towards fermentative hydrogen production. Fig. 3B depicts the patterns of the hydrogen production rate pertaining to different dosages of NiO NPs in the culture medium, for the overall fermentation period of $72 \mathrm{~h}$. The patterns were similar 
for all the experimental conditions, with the values obtained for fermentation with NiO NPs inclusion greater than the control run. Also, the hydrogen production rate was maximum by the end of $12 \mathrm{~h}$ for all fermentation runs performed with and without NiO NPs. Notably, the hydrogen productivity increased proportionally with the NPs concentration up to $1.5 \mathrm{mg} / \mathrm{L}$ and decreased for any further increase in the NPs dosage.

Many plausible reasons could elucidate the decrease in biohydrogen yield and productivity for NiO NPs concentration $>1.5 \mathrm{mg} / \mathrm{L}$. At higher concentrations, the NPs penetrates into cell membrane and releases metal ions into the cells. These ions disturbs the cell metabolism and impairs the genetic materials resulting in their preferential discharge which eventually leads to the cell death (Kumar et al., 2019). Another imperative reason for the declined biohydrogen yield and productivity for higher NPs dosage is the oxidative stress caused by these NPs which results in microbial fatality (Mishra et al., 2018). Further, the higher levels of the NPs annul the active sites concentration on hydrogenase enzyme through a bondage between the NPs and the sulphur atom of L-cysteinyl ligand molecule of the enzyme. This in turn suppress the biohydrogen yield and productivity (Han et al., 2011). Also, the higher content of the NPs might also trigger the alternate non-hydrogen based metabolic routes for sugar conversion to $\mathrm{CO}_{2}$ without hydrogen evolution (Singh et al., 2013). All these factors results in decreased biohydrogen production rate beyond the optimal NiO NPs concentration.

\subsection{CoO NPs effects on biohydrogen synthesis}

The influence of $\mathrm{CoO}$ NPs dosage on anaerobic fermentation of RMWW to produce biohydrogen was examined by differing the NPs concentration in the range of 0.5 to $3 \mathrm{mg} / \mathrm{L}$. Figs. 4A and 4B illustrate the results for the cumulative biohydrogen yield and production rate for the overall fermentation period of $72 \mathrm{~h}$. The dosage dependency results for CoO NPs were similar to that of NiO NPs. As shown in Fig. 4A, the cumulative yield of biohydrogen improved with incremental levels of CoO NPs till $1.5 \mathrm{mg} / \mathrm{L}$. At $72 \mathrm{~h}$ of fermentation time, a maximum cumulative biohydrogen yield of $195.7 \mathrm{~mL} \mathrm{H}_{2} / \mathrm{L}$ was obtained at $1.5 \mathrm{mg} / \mathrm{L}$ of $\mathrm{CoO}$ NPs as compared to other dosage levels. This was $90.4 \%$ higher than the control run without CoO NPs inclusion. However, this value was $18.7 \%$ lower than the augmented biohydrogen yield due to $\mathrm{NiO}$ NPs inclusion. Fig. 4B shows the results for the production rate variations corresponding to different concentrations of $\mathrm{CoO}$ NPs in the culture medium, for the overall fermentation period of $72 \mathrm{~h}$. The biohydrogen productivity for all the fermentation runs with and without $\mathrm{CoO}$ NPs inclusions showed a maximum at the end of $12 \mathrm{~h}$ of anaerobic digestion. Maximum biohydrogen productivity of $10.4 \mathrm{~mL} \mathrm{H}_{2} / \mathrm{L} \mathrm{h}$ was recorded for $1.5 \mathrm{mg} / \mathrm{L}$ of CoO NPs. This was 
2.05 folds higher than the control run but $32.5 \%$ lower than the productivity obtained for the same dosage of NiO NPs inclusion. Overall, the optimal dosage of $\mathrm{CoO}$ NPs for enhanced biohydrogen production from RMWW substrate using Clostridium beijerinckii DSM 791 was identified as $1.5 \mathrm{mg} / \mathrm{L}$ for given experimental conditions. Improvement in biohydrogen production characteristics by $\mathrm{CoO}$ NPs addition can be explained by the higher reaction rates associated with their interchangeable redox states. This makes the CoO NPs as crucial electron mediators during metabolic processes of hydrogen production (Mishra et al., 2018). Further, Co ions are vital cofactors for different vitamin B12 based enzymes which in turn favourably regulates the hydrogen based metabolic pathways, resulting in improved biohydrogen yield and productivity (Rodionov et al., 2006).

Higher dosage levels of CoO NPs (especially for concentrations $>1.5 \mathrm{mg} / \mathrm{L}$ ) had deleterious effect on biohydrogen yield and productivity. The core site of [Ni-Fe] hydrogenase consists of $a, b$ heterodimer. The bio-metallic active sites are present in larger $a$-subunit, whereas the smaller $b$-subunit contains Fe-S clusters which regulates a wide range of crucial biological functions, including the regulation of gene expression, substrate binding/ activation, electron transfer, and redox/non-redox catalysis. In general, the function of these iron sulphur clusters are inactivated under the presence of excessive level of Co ions (Ranquet et al., 2007). An oxidative stress might also be a possible reason for the decreased biohydrogen yield and production rate above the optimal concentration (Kumar et al., 2019).

Substantial number of works on enhancement of biohydrogen productivity through the inclusion of $\mathrm{NiO}$ and $\mathrm{CoO}$ NPs have been reported in literature. Table 1 presents a comparison on biohydrogen production improvement using $\mathrm{NiO}$ and $\mathrm{CoO}$ NPs aided dark fermentation of various organic substrates and micro-organisms. From the table, it is evident that the optimal inclusion of $\mathrm{NiO}$ and $\mathrm{CoO}$ NPs to RMWW fermentation results in better augmentation of biohydrogen yield.

\subsection{Effect of NiO and $\mathrm{CoO}$ NPs on metabolites production}

Critical analysis on the co-metabolites formation helps in understanding the metabolic pathways favoured by microbes during the fermentation process. Fig. 5A explains the concentration change effects of NiO NPs on the production of ethanol, acetate and butyrate metabolites. Increase in NiO NPs concentration, caused the corresponding increase in cometabolites production up to $1.5 \mathrm{mg} / \mathrm{L}$. At the optimal NiO NPs dosage of $1.5 \mathrm{mg} / \mathrm{L}$, the corresponding ethanol, acetate and butyrate concentrations were estimated as 2.31, 2.87 and $6.32 \mathrm{~g} / \mathrm{L}$ respectively. Further, it was also observed that the concentrations of metabolic by- 
products formed in the presence of NiO NPs were several folds higher than that of the control run without NPs inclusion. This proved the better substrate conversion efficiency due to the addition of NiO NPs to the production medium.

Among the co-metabolites formed, short chain volatile fatty acids such as acetate and butyrate were predominantly present in the fermentation medium. Hence it was concluded that the biohydrogen production in this study followed acetate and butyrate pathways. A theoretical maximum of 4 moles of hydrogen per mole of glucose is obtained when acetate is obtained as by-product. Similarly, 2 moles of hydrogen per mole of glucose is obtained when butyrate is obtained as by-product (Rambabu et al., 2019). Eqs. (10) and (11) represent the stoichiometric relationship for the acetate and butyrate pathways respectively.

$$
\mathrm{C}_{6} \mathrm{H}_{12} \mathrm{O}_{6}+\mathrm{H}_{2} \mathrm{O} \rightarrow \mathrm{C}_{2} \mathrm{H}_{5} \mathrm{OH}+\mathrm{CH}_{3} \mathrm{COOH}+2 \mathrm{H}_{2}+2 \mathrm{CO}_{2}
$$

$$
4 \mathrm{C}_{6} \mathrm{H}_{12} \mathrm{O}_{6} \rightarrow 2 \mathrm{CH}_{3} \mathrm{COOH}+3 \mathrm{CH}_{3}\left(\mathrm{CH}_{2}\right)_{2} \mathrm{COOH}+8 \mathrm{H}_{2}+8 \mathrm{CO}_{2}
$$

In general, enrichment in biohydrogen productivity is signified by increased ratio values of ethanol to acetate (E/A) and butyrate to acetate (B/A) (Rambabu et al., 2020). In this study, inclusion of NiO NPs in the fermentation system resulted in increased $\mathrm{E} / \mathrm{A}$ and $\mathrm{B} / \mathrm{A}$ ratios than the control run. Maximum ratio values of 0.804 and 2.202 were obtained for $\mathrm{E} / \mathrm{A}$ and $\mathrm{B} / \mathrm{A}$, respectively, at $1.5 \mathrm{mg} / \mathrm{L}$ of $\mathrm{NiO} \mathrm{NPs}$. This complements the fact of maximal biohydrogen production characteristics at this NPs concentration. This observation also established the existence of favourable metabolic pathway at this NPs dosage resulting in maximum biohydrogen production (Rambabu et al., 2019). The dosage dependent influence of CoO NPs on metabolites production is illustrated in Fig. 5B. The results were similar to that of NiO NPs but with lower values for the co-metabolites concentration. An increase in concentration of $\mathrm{CoO}$ NPs from 0 to $1.5 \mathrm{mg} / \mathrm{L}$ caused a corresponding increase in ethanol, acetate and butyrate concentrations from 0.41 to $1.53 \mathrm{~g} / \mathrm{L}, 0.61$ to $1.92 \mathrm{~g} / \mathrm{L}$, and 1.25 to $4.42 \mathrm{~g} / \mathrm{L}$, respectively. The $\mathrm{E} / \mathrm{A}$ and $\mathrm{B} / \mathrm{A}$ ratios obtained at optimal $\mathrm{CoO}$ NPs concentration of $1.5 \mathrm{mg} / \mathrm{L}$ were 0.797 and 2.302 , respectively, which were higher than the corresponding control run values of 0.656 and 2.049. This indicated the existence of favourable microbial metabolism that was associated with enhanced hydrogen production (Hawkes et al., 2002).

Noticeably, higher concentration of both the $\mathrm{NiO}$ and $\mathrm{CoO} \mathrm{NPs}(>1.5 \mathrm{mg} / \mathrm{L})$ resulted in lower production levels of ethanol, acetate and butyrate products. The co-metabolites formation levels for ethanol, acetate and butyrate were reduced by $51.9 \%, 36.2 \%$ and $37.9 \%$ when 
concentration of NiO NPs was boosted from 1.5 to $3 \mathrm{mg} / \mathrm{L}$. Similarly, the co-metabolites concentration was decreased by $41.8 \%, 41.4 \%$ and $54.8 \%$ for ethanol, acetate and butyrate for dosage increase of CoO NPs from 1.5 to $3 \mathrm{mg} / \mathrm{L}$. This was mainly due to carbohydrates conversion into other metabolites through non-hydrogen based metabolic pathways and decreased hydrogenase activity at higher dosages of the NPs (Mishra et al., 2018). Hence, it could be inferred that increase in the $\mathrm{NiO}$ and $\mathrm{CoO}$ NPs concentration above the optimal range reduced the co-metabolites production similar to biohydrogen synthesis. Thus, the study of cometabolites formation during fermentation provided an insight into the dominant metabolic pathway which could be used to design the optimal conditions favourable for higher biohydrogen production characteristics.

\subsection{Biomass and COD reduction efficiency}

Biomass estimation and COD reduction efficiency were the other parameters that were examined to assess the effect of the NPs addition in the anaerobic digestion of RMWW. The results for the variations in microbial biomass concentration and COD reduction efficiency (after $12 \mathrm{~h}$ of fermentation) with respect to different concentrations of the NPs are depicted in Fig. 6A and Fig. 6B, respectively. As shown in Fig. 6A, it could be seen that the total cell density improved with the increase in the NPs concentration for both $\mathrm{NiO}$ and $\mathrm{CoO}$ till their optimal value of $1.5 \mathrm{mg} / \mathrm{L}$. Further dosage increase of the NPs resulted in relatively lower cell population. However, fermentation in the presence of NPs produced higher biomass concentration than fermentation without NPs. This observation proved the beneficial roles of the NPs inclusion for microbial growth and multiplication. Maximum biomass concentrations of $3.93 \mu \mathrm{g} / \mathrm{L}$ and $3.51 \mu \mathrm{g} / \mathrm{L}$ were obtained at $1.5 \mathrm{mg} / \mathrm{L}$ of NiO and $\mathrm{CoO}$ NPs concentration, respectively. This was approximately two folds higher than the growth of biomass in the control run. The positive role of $\mathrm{Ni}$ and $\mathrm{Co}$ ions for the fermentative metabolic reactions of bacteria have already been reported by Bini, 2010. Several micro-organisms show high affinity for Ni and Co metal uptake to achieve metabolic homeostasis and enzyme enrichment (Rodionov et al., 2006). These facts establish the favourable effects of $\mathrm{Ni}$ and Co metal ions inclusion to the culture medium.

Higher dosage levels of the NPs $(>1.5 \mathrm{mg} / \mathrm{L})$ resulted in decreased microbial biomass concentration for both $\mathrm{NiO}$ and $\mathrm{CoO}$ NPs assisted hydrogen fermentation. The cell population was drastically reduced by $49.6 \%$ and $46.4 \%$ from their maximum values when the NPs concentration was varied to $3 \mathrm{mg} / \mathrm{L}$ for both $\mathrm{NiO}$ and $\mathrm{CoO}$ NPs. The production of reactive oxygen species at these high concentrations of NPs resulted in cell toxicity and ceasing of 
bacterial viability, which attributed to decreased bacterial concentration (Kumar et al., 2019; Lin et al., 2016). The results obtained for the biomass concentration variations with dosage changes of NPs were in line with the results for biohydrogen and co-metabolites production.

In general, COD is the measure of amount of organic content present in the waste-water. COD reduction efficiency is an important characteristic in biohydrogen production since it determines the rational selection of the micro-organism in hydrogen production, and the simultaneous wastewater treatment process. The ability of a micro-organism to reduce COD implies its efficiency towards the conversion of the waste organics in the substrate to hydrogen and other evolved gases (Gadhe et al., 2015a). The impact of NiO and CoO NPs on COD reduction efficiency during biohydrogen production from RMWW is depicted in Fig. 6B. From the figure, it is evident that the inclusion of these metal NPs increased the COD reduction in the RMWW. The COD reduction efficiency reached a maximum of $77.6 \%$ and $69.5 \%$ for optimal dosage of $1.5 \mathrm{mg} / \mathrm{L}$ for the $\mathrm{NiO}$ and $\mathrm{CoO}$ NPs respectively. This was considerably higher than that of control run which recorded 57.5\% of COD removal. Dosage levels of NPs higher than the optimal concentration resulted in relatively lower COD removal efficiencies. This again elucidated the importance of dose dependent effects of metal oxide NPs for wastewater treatment.

$\mathrm{Ni}$ ions are the core entities present in the active centre of [ $\mathrm{Ni}-\mathrm{Fe}]$ hydrogenase and hence their optimal supplementation to the fermentation medium accelerated the hydrogen production from the organic wastes present in RMWW (Mishra et al., 2018). Further, Co ions are essential cofactors for large number of enzymes including nitrile hydratase, prolidase, methyl malonylCoA carboxyltransferase and methionine aminopeptidase that play a vital role in various metabolic processes. An ideal dosage of Co ions aids the metabolic routes of organics decomposition by the micro-organisms which resulted in COD reduction of the RMWW (Qiang et al., 2012). Thus NPs at their optimal concentration have an ability to stimulate the growth of fermentative bacterium and metabolism of key enzymes required for anaerobic digestion of waste water (Wang and Chen, 2016). A close analysis on the results showed the better stimulatory action of NiO NPs than the CoO NPs which confirmed the dominant contribution of [Ni-Fe] hydrogenase for biohydrogen production from RMWW.

\subsection{Biohydrogen kinetic modeling}

Kinetic analysis on the anaerobic fermentation of RMWW to produce biohydrogen provides vital information on the theoretical maximum of biohydrogen production characteristics (Rambabu et al., 2020). The analysis serves as an imperative tool for scale-up 
studies of the lab mode batch fermentation into commercial production (Pal et al., 2018). Critical kinetic parameters like lag phase time of hydrogen production $(\lambda)$, maximum hydrogen production rate $\left(M_{R}\right)$ and maximum potential for hydrogen yield $\left(M_{Y}\right)$ that influence the biohydrogen synthesis from RMWW were studied by fitting the experimental data with two different kinetic models, namely Gompertz model and modified Logistic model.

The results obtained for kinetic modeling of NiO NPs assisted biohydrogen production is presented in Table 2. Hydrogen production potential and hydrogen production rate increased with the addition of NiO NPs upto $1.5 \mathrm{mg} / \mathrm{L}$. Maximal hydrogen production rates of $13 \mathrm{~mL}$ $\mathrm{H}_{2} / \mathrm{L} \mathrm{h}$ and $20.08 \mathrm{~mL} \mathrm{H}_{2} / \mathrm{L} \mathrm{h}$ were obtained for NiO NPs concentration of $1.5 \mathrm{mg} / \mathrm{L}$ in Gompertz and modified Logistic models respectively. Further, the models predicted a drastic reduction in the lag phase of fermentation due to the NiO NPs inclusion. Remarkably, Gompertz model estimated a shorter lag phase time than that of the modified Logistic model. In general, biohydrogen production occurs between the lag phase and stationary phase of bacterial growth curve (Swathy et al., 2019). Thus, an addition of NiO NPs into the RMWW medium decreased the lag phase period to considerable level and prolonged the biohydrogen production span for a longer time. This resulted in enhanced biohydrogen production characteristics. The theoretical maximum hydrogen yield for the optimal NPs dosage of $1.5 \mathrm{mg} / \mathrm{L}$ was computed as $198.99 \mathrm{~mL} \mathrm{H}_{2} / \mathrm{L}$ and $196.01 \mathrm{~mL} \mathrm{H}_{2} / \mathrm{L}$ by the Gompertz and modified Logistic models.

The biohydrogen production parameters obtained from the kinetic analysis of the $\mathrm{CoO}$ NPs aided dark fermentative biohydrogen production is presented in Table 3. The hydrogen production potential and cumulative hydrogen production rate evaluated for $\mathrm{CoO}$ NPs followed a trend similar to that of NiO NPs. Minimal lag phase period of $0.49 \mathrm{~h}$ was obtained in Gompertz model for the optimal $\mathrm{CoO}$ NPs concentration of $1.5 \mathrm{mg} / \mathrm{L}$. Also, theoretical maximum biohydrogen yields of $181.11 \mathrm{~mL} \mathrm{H} / \mathrm{L}$ and $177.11 \mathrm{~mL} \mathrm{H}_{2} / \mathrm{L}$ were obtained by Gompertz and modified Logistic models at this ideal CoO NPs dosage.

Importantly, a relatively higher $R^{2}$ value and minimal $\lambda$ value was computed for all the regression fits of Gompertz model as compared to that of modified Logistic model, for both $\mathrm{NiO}$ and $\mathrm{CoO}$ NPs assisted fermentations. This proved the goodness and reliability of Gompertz model in estimating the impact of nano metal oxides on biohydrogen production from the anaerobic digestion of RMWW. Moreover the theoretical maximal values were consistent with their respective experimental equivalents for the both NPs additives which is a clear indication of the fact that other fermentation parameters were also in line with their optimized values (Rambabu et al., 2014). 
Thus, easy and efficient techniques for biohydrogen production enrichment would transfer the fermentation technology from lab scale to industrial scale to cater the growing energy demand. This study showed that the incorporation of NiO and $\mathrm{CoO}$ NPs augments the biohydrogen production characteristics in a remarkable manner. The preliminary results for the NPs assisted fermentation batch study proved the individual ability and identified the optimum concentration of $\mathrm{NiO}$ and $\mathrm{CoO}$ NPs for enriched biohydrogen production from RMWW. Analysis on the combined effects of $\mathrm{NiO}$ and $\mathrm{CoO}$ on biohydrogen productivity along with a detailed examination on the influence of other operational conditions (such as $\mathrm{pH}$ and temperature) for the NPs assisted RMWW fermentation would be an assuring future scope of this work. Also, techno-economic feasibility studies for continuous biohydrogen production with necessary process simulation could be carried out as a continual research effort of the reported work.

\section{Conclusions}

The reported study focused on the enhancement of biohydrogen productivity through the inclusion of $\mathrm{NiO}$ and $\mathrm{CoO}$ NPs to the RMWW fermentation medium under the action of anaerobic digestion by Clostridium beijerinckii DSM 791. The NPs prepared by a facile hydrothermal process showed polyhedral morphology, high product purity, and particle sizes of $26.3 \mathrm{~nm}(\mathrm{NiO})$ and $50.1 \mathrm{~nm}(\mathrm{CoO})$. The NPs assisted dark fermentation studies showed that for an optimal dosage of $1.5 \mathrm{mg} / \mathrm{L}$, the biohydrogen yield was increased by 2.1 and 1.9 times for both the $\mathrm{NiO}$ and $\mathrm{CoO}$ addition respectively, as compared to control run without NPs inclusion. Also, the maximum hydrogen productivity observed at end of $12 \mathrm{~h}$ fermentation period was 2.4 and 2 folds higher for this ideal concentration of NiO and $\mathrm{CoO}$ NPs respectively, than the control run. Metabolites analysis elucidated the biohydrogen production through butyrate and acetate pathways. Further, the NPs incorporation improved the cell proliferation and COD reduction efficiency. Kinetic analysis revealed that the Gompetz model predicted the experimental data better than the modified Logistic function models for both NPs. A close analysis on the results showed the better stimulatory effects of NiO NPs than CoO NPs. Thus, the overall study established the addition of $\mathrm{NiO}$ and $\mathrm{CoO}$ NPs as a viable method to augment the biohydrogen production from RMWW fermentation and similar wastewater sources.

\section{Acknowledgements}


Authors are grateful to Khalifa University of Science, Technology \& Research for

604

605

606

607

608

609

610

611

612

613

614

615

616

617

618

619

620

621

622

623

624

625

626

627

628

629

630

631

632

633

634

635

636

providing necessary financial support to this research work through the project\# CIRA-2019028 under the Competitive Internal Research Award scheme.

\section{References}

[1] American Public Health Association (APHA), American Water Works Association (AWWA), Water Environment Federation (WEF), 2005. Standard Methods for the Examination of Water and Wastewater, 21st Ed., Washington DC.

[2] Bharath, G., Rambabu, K., Banat, F., Hai, A., Arangadi, A.F., Ponpandian, N., 2019. Enhanced electrochemical performances of peanut shell derived activated carbon and its Fe3O4 nanocomposites for capacitive deionization of Cr(VI) ions. Sci. Total Environ. 691, 713-726 https://doi.org/10.1016/j.scitotenv.2019.07.069

[3] Bharath, G., Rambabu, K., Hai, A., Anwer, S., Banat, F., Ponpandian, N., 2020a. Synthesis of one-dimensional magnetite hydroxyapatite nanorods on reduced graphene oxide sheets for selective separation and controlled delivery of hemoglobin. Appl. Surf. Sci. 501, 144215. https://doi.org/10.1016/j.apsusc.2019.144215

[4] Bharath, G., Rambabu, K., Hai, A., Taher, H., Banat, F., 2020b. Development of Au and 1D Hydroxyapatite Nanohybrids Supported on 2D Boron Nitride Sheets as Highly Efficient Catalysts for Dehydrogenating Glycerol to Lactic Acid. ACS Sustain. Chem. Eng. 8, 7278-7289. https://doi.org/10.1021/acssuschemeng.9b06997

[5] Bini, E., 2010. Archaeal transformation of metals in the environment. FEMS Microbiol. Ecol. 73, 1-16. https://doi.org/10.1111/j.1574-6941.2010.00876.x

[6] Chen, J., Yun, S., Shi, J., Wang, Z., Abbas, Y., Wang, K., Han, F., Jia, B., Xu, H., Xing, T., Li, B., 2020. Role of biomass-derived carbon-based composite accelerants in enhanced anaerobic digestion: Focusing on biogas yield, fertilizer utilization, and density functional theory calculations. Bioresour. Technol. 307, 123204. https://doi.org/10.1016/j.biortech.2020.123204

[7] Choudhary, M., Majumder, S., Neogi, S., 2015. Studies on the Treatment of Rice Mill Effluent by Electrocoagulation. Sep. Sci. Technol. 50, 505-511. https://doi.org/10.1080/01496395.2014.956225

[8] Desvaux, M., 2006. Unravelling carbon metabolism in anaerobic cellulolytic bacteria. Biotechnol. Prog. 22, 1229-1238. https://doi.org/10.1021/bp060016e

[9] Engliman, N.S., Abdul, P.M., Wu, S.Y., Jahim, J.M., 2017. Influence of iron (II) oxide nanoparticle on biohydrogen production in thermophilic mixed fermentation. Int. J. 

Hydrogen Energy 42, 27482-27493. https://doi.org/10.1016/j.ijhydene.2017.05.224

[10] Fonseca, B.C., Riaño-Pachón, D.M., Guazzaroni, M.E., Reginatto, V., 2019. Genome sequence of the $\mathrm{H} 2$-producing clostridium beijerinckii strain $\mathrm{Br} 21$ isolated from a sugarcane vinasse treatment plant. Genet. Mol. Biol. 42, 144-149. https://doi.org/10.1590/1678-4685-gmb-2017-0315

[11] Gadhe, A., Sonawane, S.S., Varma, M.N., 2015a. Enhancement effect of hematite and nickel nanoparticles on biohydrogen production from dairy wastewater. Int. J. Hydrogen Energy 40, 4502-4511. https://doi.org/10.1016/j.ijhydene.2015.02.046

[12] Gadhe, A., Sonawane, S.S., Varma, M.N., 2015b. Influence of nickel and hematite nanoparticle powder on the production of biohydrogen from complex distillery wastewater in batch fermentation. Int. J. Hydrogen Energy 40, 10734-10743. https://doi.org/10.1016/j.ijhydene.2015.05.198

[13] Han, H., Cui, M., Wei, L., Yang, H., Shen, J., 2011. Enhancement effect of hematite nanoparticles on fermentative hydrogen production. Bioresour. Technol. 102, 79037909. https://doi.org/10.1016/j.biortech.2011.05.089

[14] Hawkes, F.R., Dinsdale, R., Hawkes, D.L., Hussy, I., 2002. Sustainable fermentative hydrogen production: Challenges for process optimisation. Int. J. Hydrogen Energy 27, 1339-1347. https://doi.org/10.1016/S0360-3199(02)00090-3

[15] Jiang, Y., Chen, D., Song, J., Jiao, Z., Ma, Q., Zhang, H., Cheng, L., Zhao, B., Chu, Y., 2013. A facile hydrothermal synthesis of graphene porous $\mathrm{NiO}$ nanocomposite and its application in electrochemical capacitors. Electrochim. Acta 91, 173-178. https://doi.org/10.1016/j.electacta.2012.12.032

[16] Kumar, G., Mathimani, T., Rene, E.R., Pugazhendhi, A., 2019. Application of nanotechnology in dark fermentation for enhanced biohydrogen production using inorganic nanoparticles. Int. J. Hydrogen Energy 44, 13106-13113. https://doi.org/10.1016/j.ijhydene.2019.03.131

[17] Leong, Y.K., Show, P.L., Lan, J.C.W., Krishnamoorthy, R., Chu, D.T., Nagarajan, D., Yen, H.W., Chang, J.S., 2019. Application of thermo-separating aqueous two-phase system in extractive bioconversion of polyhydroxyalkanoates by Cupriavidus necator H16. Bioresour. Technol. 287, 121474. https://doi.org/10.1016/j.biortech.2019.121474

[18] Lin, R., Cheng, J., Ding, L., Song, W., Liu, M., Zhou, J., Cen, K., 2016. Enhanced dark hydrogen fermentation by addition of ferric oxide nanoparticles using Enterobacter aerogenes. Bioresour. Technol. 207, 213-219. https://doi.org/10.1016/j.biortech.2016.02.009 
[19] Mishra, P., Singh, L., Amirul Islam, M., Nasrullah, M., Mimi Sakinah, A.M., Wahid, Z.A., 2019. $\mathrm{NiO}$ and $\mathrm{CoO}$ nanoparticles mediated biological hydrogen production: Effect of Ni/Co oxide NPs-ratio. Bioresour. Technol. Reports 5, 364-368. https://doi.org/10.1016/j.biteb.2018.02.004

[20] Mishra, P., Thakur, S., Mahapatra, D.M., Wahid, Z.A., Liu, H., Singh, L., 2018. Impacts of nano-metal oxides on hydrogen production in anaerobic digestion of palm oil mill effluent - A novel approach. Int. J. Hydrogen Energy 43, 2666-2676. https://doi.org/10.1016/j.ijhydene.2017.12.108

[21] Pal, P., Edathil, A.A., Chaurasia, L., Rambabu, K., Banat, F., 2018. Removal of sulfide from aqueous solutions using novel alginate-iron oxide magnetic hydrogel composites. Polym. Bull. 75, 5455-5475. https://doi.org/10.1007/s00289-018-2338-6

[22] Pan, Z., Zhang, R., Zicari, S., 2019. Integrated Processing Technologies for Food and Agricultural By-Products, Integrated Processing Technologies for Food and Agricultural By-Products. 1st Ed. Elsevier, Amsterdam. https://doi.org/10.1016/C20170-00901-1

[23] Pawar, S.S., Van Niel, E.W.J., 2013. Thermophilic biohydrogen production: How far are we? Appl. Microbiol. Biotechnol. 97, 7999-8009. https://doi.org/10.1007/s00253013-5141-1

[24] Qiang, H., Lang, D.L., Li, Y.Y., 2012. High-solid mesophilic methane fermentation of food waste with an emphasis on Iron, Cobalt, and Nickel requirements. Bioresour. Technol. 103, 21-27. https://doi.org/10.1016/j.biortech.2011.09.036

[25] Rambabu, K., Bharath, G., Banat, F., Hai, A., Show, P.L., Phong Nguyen, T.H., 2020. Ferric oxide/date seed activated carbon nanocomposites mediated dark fermentation of date fruit wastes for enriched biohydrogen production. Int. J. Hydrogen Energy. In press. https://doi.org/10.1016/j.ijhydene.2020.06.108

[26] Rambabu, K., Bharath, G., Banat, F., Show, P.L., 2021. Green synthesis of zinc oxide nanoparticles using Phoenix dactylifera waste as bioreductant for effective dye degradation and antibacterial performance in wastewater treatment. J. Hazard. Mater. 402, 123560. https://doi.org/10.1016/j.jhazmat.2020.123560

[27] Rambabu, K., Muruganandam, L., Velu, S., 2014. CFD simulation for separation of carbon dioxide-methane mixture by pressure swing adsorption. Int. J. Chem. Eng. 2014, 402756. https://doi.org/10.1155/2014/402756

[28] Rambabu, K., Show, P.L., Bharath, G., Banat, F., Naushad, M., Chang, J.S., 2019. Enhanced biohydrogen production from date seeds by Clostridium thermocellum 
ATCC 27405. Int. J. Hydrogen Energy 45, 22271-22280. https://doi.org/10.1016/j.ijhydene.2019.06.133

[29] Ramprakash, B., Muthukumar, K., 2014. Comparative study on the production of biohydrogen from rice mill wastewater. Int. J. Hydrogen Energy 39, 14613-14621. https://doi.org/10.1016/j.ijhydene.2014.06.029

[30] Ranquet, C., Ollagnier-de-Choudens, S., Loiseau, L., Barras, F., Fontecave, M., 2007. Cobalt stress in Escherichia coli: The effect on the iron-sulfur proteins. J. Biol. Chem. 282, 30442-30451. https://doi.org/10.1074/jbc.M702519200

[31] Rodionov, D.A., Hebbeln, P., Gelfand, M.S., Eitinger, T., 2006. Comparative and functional genomic analysis of prokaryotic nickel and cobalt uptake transporters: Evidence for a novel group of ATP-binding cassette transporters. J. Bacteriol. 188, 317327. https://doi.org/10.1128/JB.188.1.317-327.2006

[32] Singer, S., Magnusson, L., Hou, D., Lo, J., Maness, P.C., Ren, Z.J., 2018. Anaerobic membrane gas extraction facilitates thermophilic hydrogen production from Clostridium thermocellum. Environ. Sci. Water Res. Technol. 4, 1771-1782. https://doi.org/10.1039/c8ew00289d

[33] Singh, L., Siddiqui, M.F., Ahmad, A., Rahim, M.H.A., Sakinah, M., Wahid, Z.A., 2013. Application of polyethylene glycol immobilized Clostridium sp. LS2 for continuous hydrogen production from palm oil mill effluent in upflow anaerobic sludge blanket reactor. Biochem. Eng. J. 70, 158-165. https://doi.org/10.1016/j.bej.2012.10.010

[34] Skonieczny, M.T., Yargeau, V., 2009. Biohydrogen production from wastewater by Clostridium beijerinckii: Effect of $\mathrm{pH}$ and substrate concentration. Int. J. Hydrogen Energy 34, 3288-3294. https://doi.org/10.1016/j.ijhydene.2009.01.044

[35] Swathy, R., Rambabu, K., Banat, F., Ho, S.H., Chu, D.T., Show, P.L., 2019. Production and optimization of high grade cellulase from waste date seeds by Cellulomonas uda NCIM 2353 for biohydrogen production. Int. J. Hydrogen Energy 45, 22260-22270. https://doi.org/10.1016/j.ijhydene.2019.06.171

[36] Tao, D., Wei, F., 2004. New procedure towards size-homogeneous and well-dispersed nickel oxide nanoparticles of $30 \mathrm{~nm}$. Mater. Lett. 58, 3226-3228. https://doi.org/10.1016/j.matlet.2004.06.015

[37] Trchounian, K., Müller, N., Schink, B., Trchounian, A., 2017. Glycerol and mixture of carbon sources conversion to hydrogen by Clostridium beijerinckii DSM791 and effects of various heavy metals on hydrogenase activity. Int. J. Hydrogen Energy 42, 
188

7875-7882. https://doi.org/10.1016/j.ijhydene.2017.01.011

[38] Wang, D., Chen, Y., 2016. Critical review of the influences of nanoparticles on biological wastewater treatment and sludge digestion. Crit. Rev. Biotechnol. 36, 816828. https://doi.org/10.3109/07388551.2015.1049509

[39] Wu, H., Wang, Y., Zheng, C., Zhu, J., Wu, G., Li, X., 2016. Multi-shelled NiO hollow spheres: Easy hydrothermal synthesis and lithium storage performances. J. Alloys Compd. 685, 8-14. https://doi.org/10.1016/j.jallcom.2016.05.264

[40] Zhang, Jishi, Fan, C., Zhang, H., Wang, Z., Zhang, Junjie, Song, M., 2018. Ferric oxide/carbon nanoparticles enhanced bio-hydrogen production from glucose. Int. J. Hydrogen Energy 43, 8729-8738. https://doi.org/10.1016/j.ijhydene.2018.03.143

[41] Zhong, D., Liao, X., Liu, Y., Zhong, N., Xu, Y., 2018. Enhanced electricity generation performance and dye wastewater degradation of microbial fuel cell by using a petaline NiO@polyaniline-carbon felt anode. Bioresour. Technol. 258, 125-134. https://doi.org/10.1016/j.biortech.2018.01.117

(a)

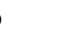

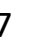

每

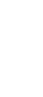

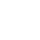

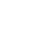

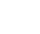

(1)

年

.

(1)

\section{List of Figures:}


770 Fig. 1 SEM micrographs and EDX spectrum of the NPs - (A) \& (B) $\mathrm{NiO}$ and (C) \& (D) $\mathrm{CoO}$ 771 Fig. 2 (A) XRD patterns and (B) Particle size distribution of the NPs

772 Fig. 3 Influence of NiO NPs on (A) cumulative hydrogen yield and (B) hydrogen productivity 773 from RMWW

774 Fig. 4 Influence of $\mathrm{CoO}$ NPs on (A) cumulative hydrogen yield and (B) hydrogen productivity 775 from RMWW

776 Fig. 5 Effect of nano-metal oxides on the concentrations of soluble co-metabolites (A) NiO

777 NPs and (B) CoO NPs

778 Fig. 6 Impact of NPs on (A) Biomass concentration and (B) COD removal, after $12 \mathrm{~h}$ of 779 fermentation

780

781

782

783

784

785

786

787

788

789

790

791

792

793

794

795

796

797

798

799

800

801

802 


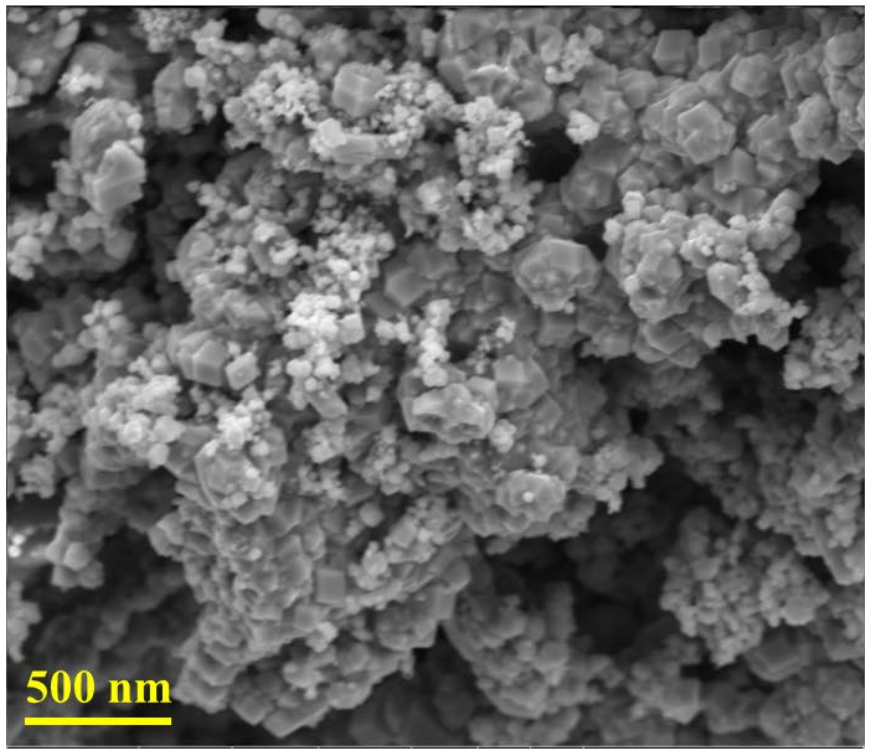

(A)

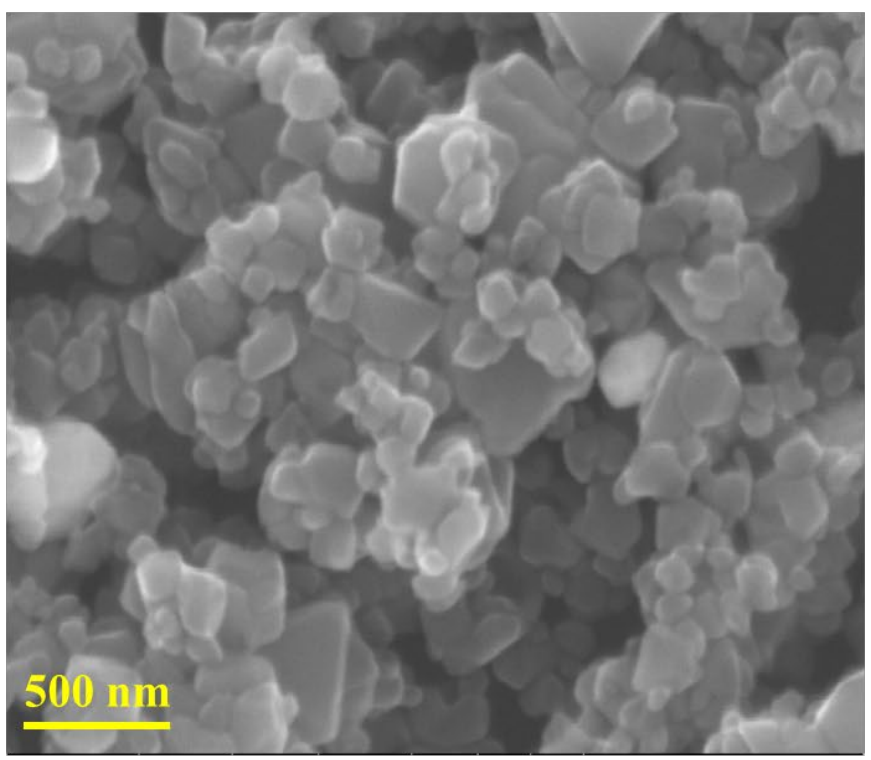

(C)

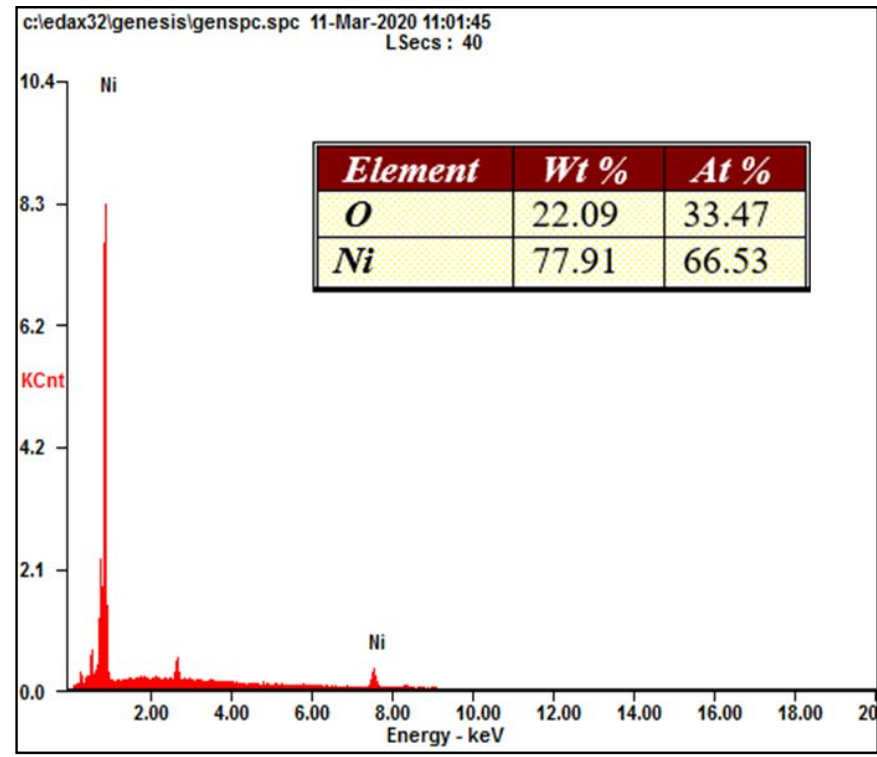

(B)

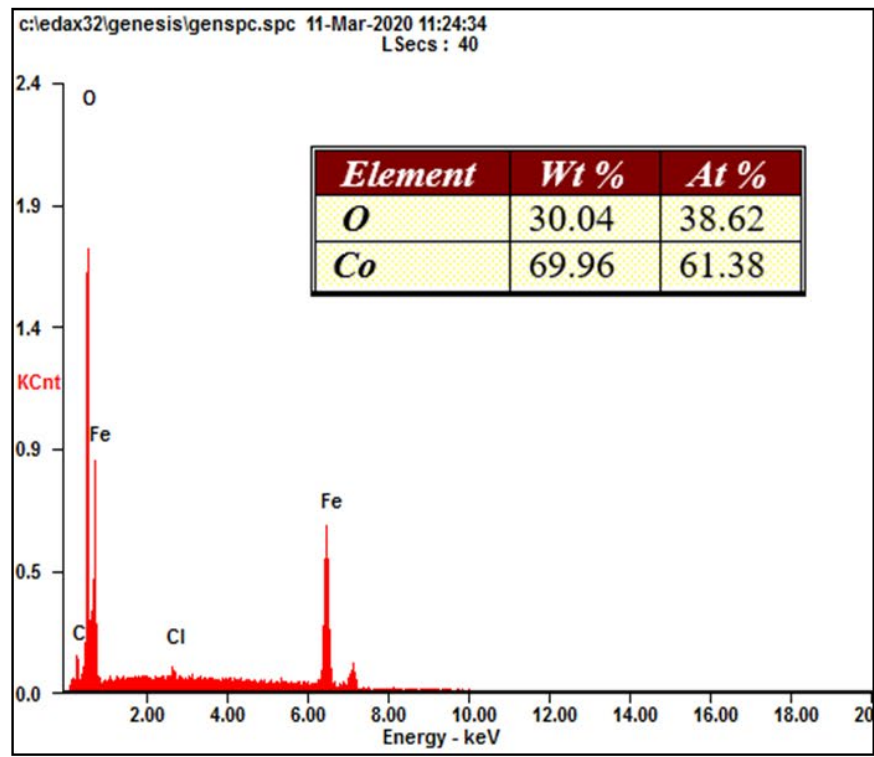

(D)

803

804 Fig. 1 SEM micrographs and EDX spectrum of the NPs - (A) \& (B) $\mathrm{NiO}$ and (C) \& (D)

$805 \mathrm{CoO}$

806

807 


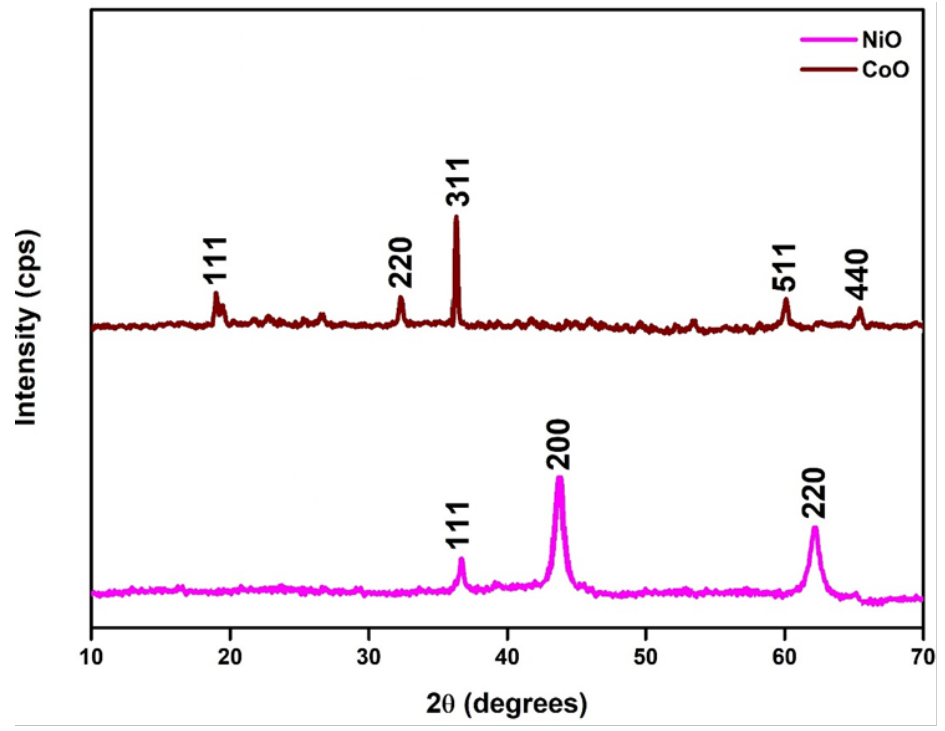

(A)
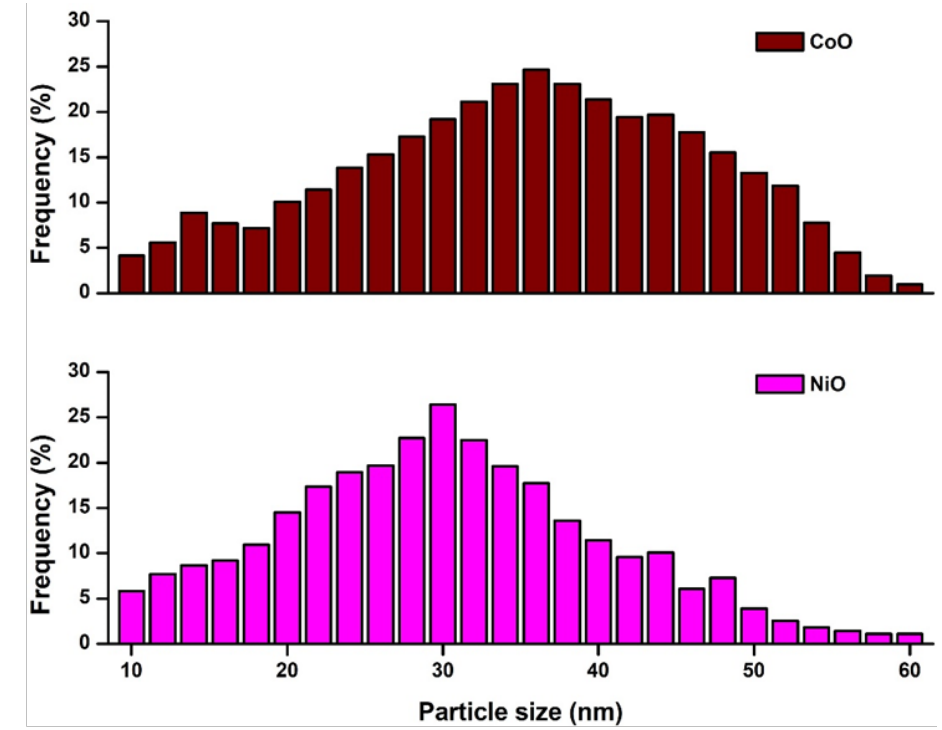

(B)

808

Fig. 2 (A) XRD patterns and (B) Particle size distribution of the NPs

809

810

811

812

813

814

815

816

817

818

819

820

821

822

823

824

825

826

827

828

829 


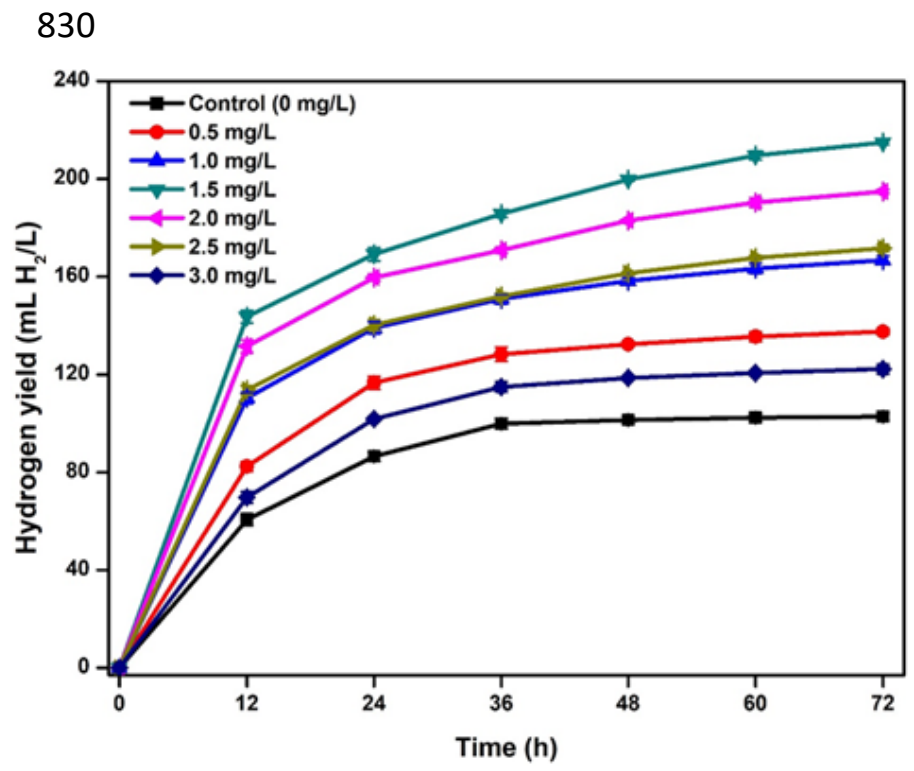

(A)

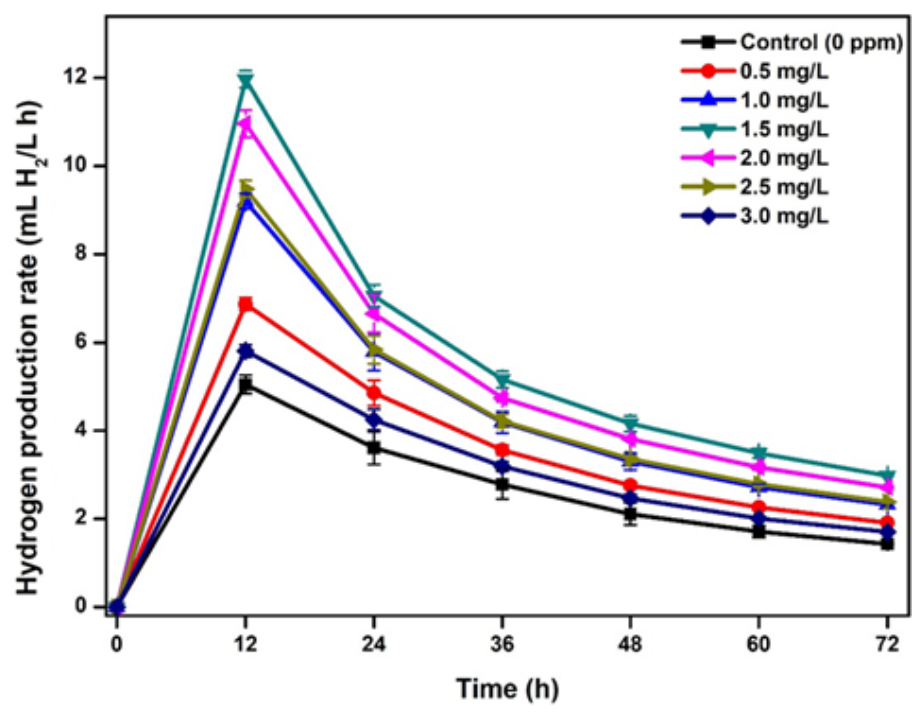

(B)

832 Fig. 3 Influence of NiO NPs on (A) cumulative hydrogen yield and (B) hydrogen productivity 833 from RMWW

834

835

836

837

838

839

840

841

842

843

844

845

846

847

848

849

850

851

852 
853

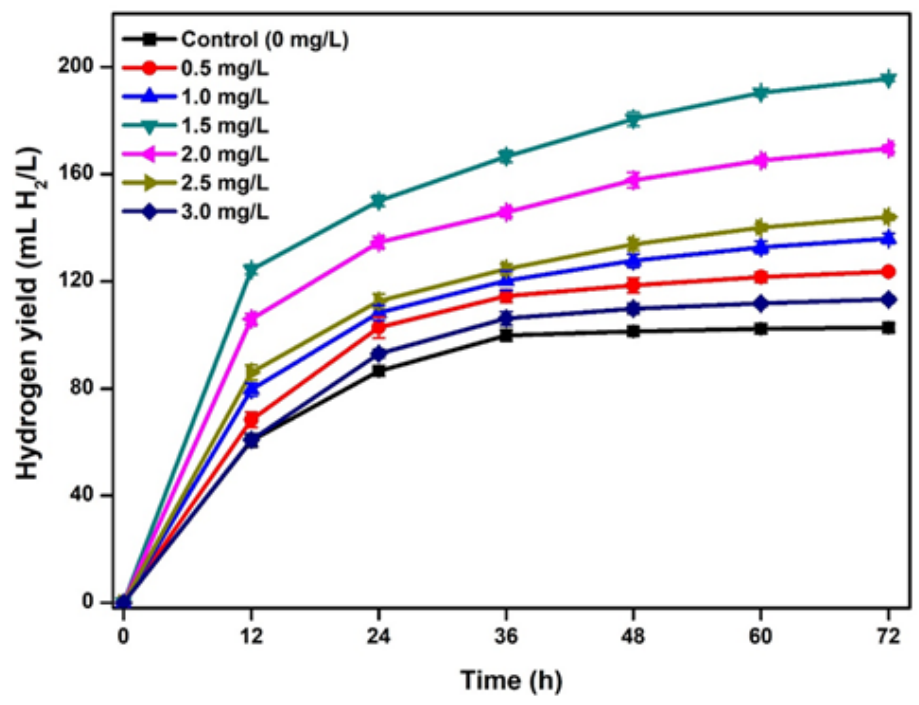

(A)

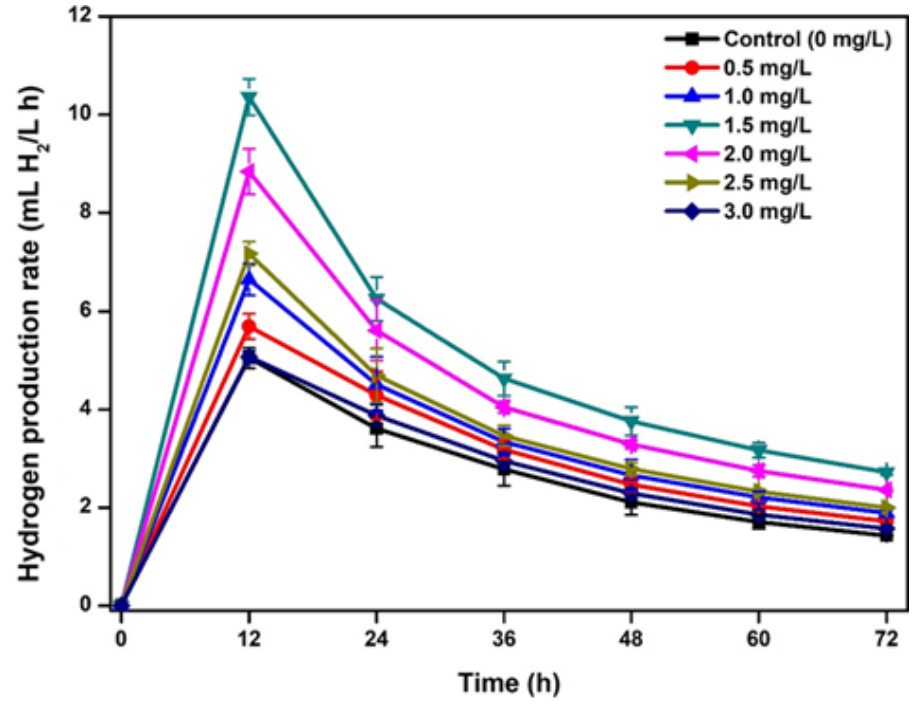

(B)

855 Fig. 4 Influence of $\mathrm{CoO}$ NPs on (A) cumulative hydrogen yield and (B) hydrogen

856 productivity from RMWW

857

858

859

860

861

862

863

864

865

866

867

868

869

870

871

872

873

874

875 


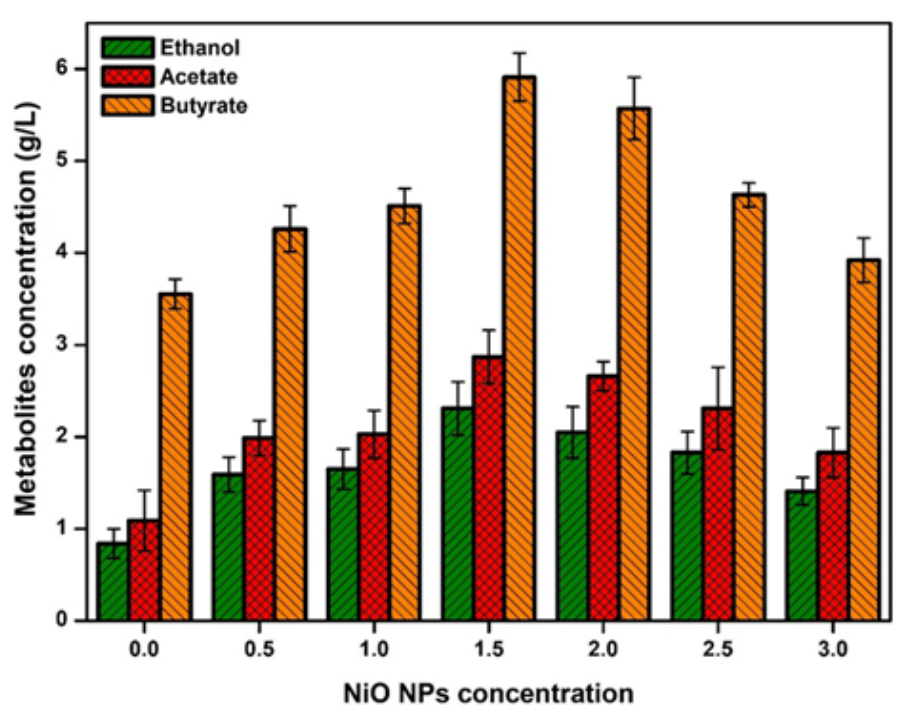

(A)

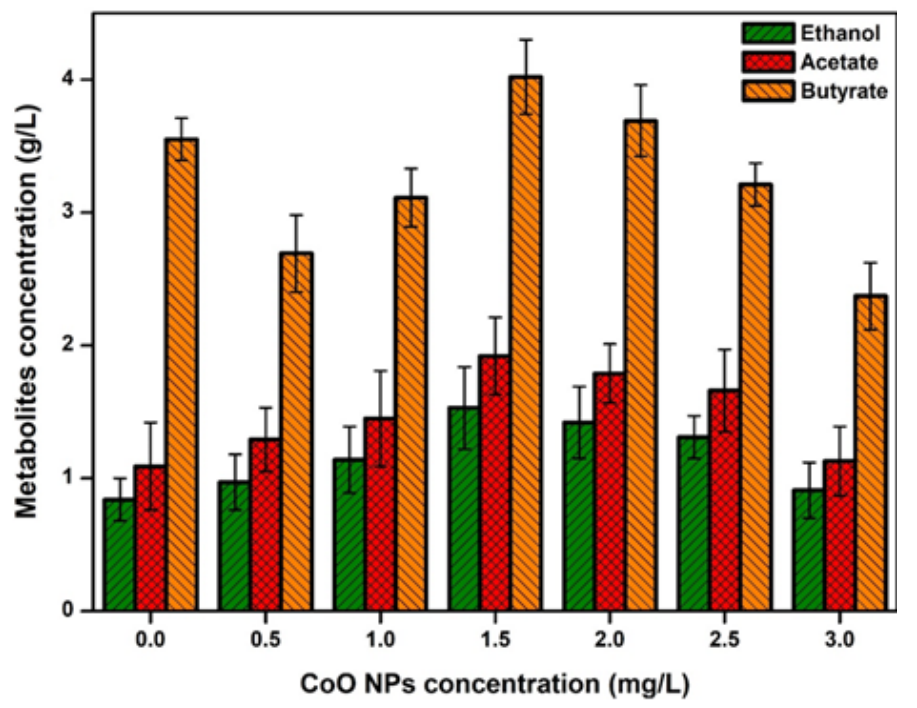

(B)

878 Fig. 5 Effect of nano-metal oxides on the concentrations of soluble co-metabolites (A) NiO

$879 \quad$ NPs and (B) CoO NPs

880

881

882

883

884

885

886

887

888

889

890

891

892

893

894

895

896

897 


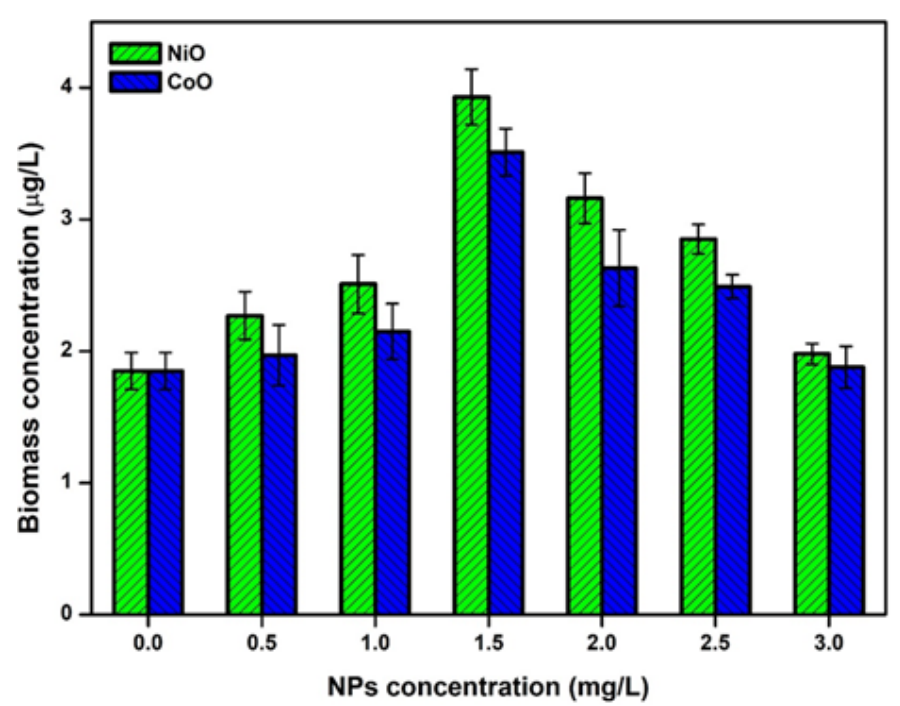

(A)

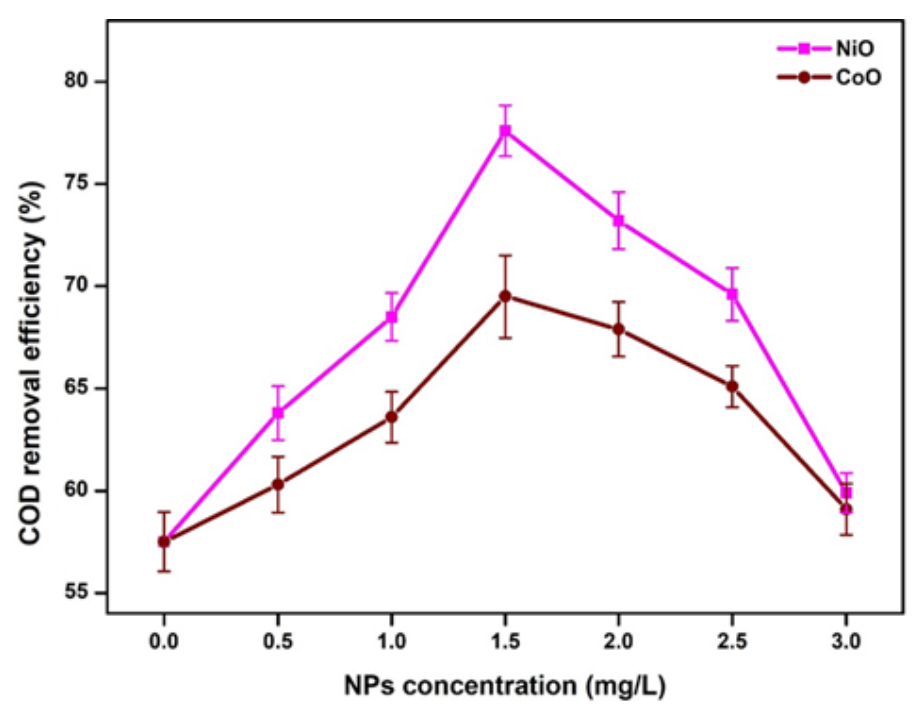

(B)

901 Fig. 6 Impact of NPs on (A) Biomass concentration and (B) COD removal, after $12 \mathrm{~h}$ of 902 fermentation

903

904

905

906

907

908

909

910

911

912

913

914

915

916

917

918

919

920

921 
$922 \quad$ List of Tables:

923 Table 1 Comparative studies on influence of NiO and $\mathrm{CoO}$ NPs assisted fermentative bio-

924 hydrogen yield

925 Table 2 Kinetic parameters for biohydrogen production from RMWW using NiO NPs

926 Table 3 Kinetic parameters for biohydrogen production from RMWW using CoO NPs 927

928

929

930

931

932

933

934

935

936

937

938

939

940

941

942

943

944

945

946

947

948

949

950

951

952

953

954 
955 Table 1 Comparative studies on influence of NiO and $\mathrm{CoO}$ NPs assisted fermentative bio956 hydrogen yield

\begin{tabular}{|c|c|c|c|c|c|}
\hline $\begin{array}{l}\text { Substrate } \\
\text { type }\end{array}$ & $\begin{array}{l}\text { Biological } \\
\text { agent }\end{array}$ & $\begin{array}{l}\text { Metal oxide } \\
\text { based NPs }\end{array}$ & $\begin{array}{l}\text { NPs dosage } \\
(\mathrm{mg} / \mathrm{L})\end{array}$ & $\begin{array}{l}\text { Bio-H2 yield } \\
\text { enhancement }\end{array}$ & Reference \\
\hline $\begin{array}{l}\text { Glucose } \\
\text { and starch }\end{array}$ & $\begin{array}{l}\text { Anaerobic } \\
\text { sludge }\end{array}$ & $\mathrm{NiO}$ & 200 & $5.5 \%$ & $\begin{array}{l}\text { (Engliman } \\
\text { et al., 2017) }\end{array}$ \\
\hline $\begin{array}{l}\text { Dairy } \\
\text { wastewater }\end{array}$ & $\begin{array}{l}\text { Anaerobic } \\
\text { sludge }\end{array}$ & $\mathrm{NiO}$ & 10 & $16 \%$ & $\begin{array}{l}\text { (Gadhe et } \\
\text { al., 2015a) }\end{array}$ \\
\hline $\begin{array}{l}\text { Dairy } \\
\text { wastewater }\end{array}$ & $\begin{array}{l}\text { Anaerobic } \\
\text { sludge }\end{array}$ & $\mathrm{NiO}+\mathrm{Fe}_{2} \mathrm{O}_{3}$ & 10 & $27 \%$ & $\begin{array}{l}\text { (Gadhe et } \\
\text { al., 2015a) }\end{array}$ \\
\hline $\begin{array}{l}\text { Distillery } \\
\text { wastewater }\end{array}$ & $\begin{array}{l}\text { Anaerobic } \\
\text { sludge }\end{array}$ & $\mathrm{NiO}$ & 5 & $24 \%$ & $\begin{array}{l}\text { (Gadhe et } \\
\text { al., 2015b) }\end{array}$ \\
\hline $\begin{array}{l}\text { Distillery } \\
\text { wastewater }\end{array}$ & $\begin{array}{l}\text { Anaerobic } \\
\text { sludge }\end{array}$ & $\mathrm{NiO}+\mathrm{Fe}_{2} \mathrm{O}_{3}$ & $5+200$ & $62 \%$ & $\begin{array}{l}\text { (Gadhe et } \\
\text { al., 2015b) }\end{array}$ \\
\hline $\begin{array}{l}\text { Palm oil } \\
\text { mill } \\
\text { effluent }\end{array}$ & $\begin{array}{l}\text { Bacillus } \\
\text { anthracis } \\
\text { PUNAJAN } 1\end{array}$ & $\mathrm{NiO}$ & 1.5 & $35.2 \%$ & $\begin{array}{l}\text { (Mishra et } \\
\text { al., 2018) }\end{array}$ \\
\hline $\begin{array}{l}\text { Palm oil } \\
\text { mill } \\
\text { effluent }\end{array}$ & $\begin{array}{l}\text { Bacillus } \\
\text { anthracis } \\
\text { PUNAJAN 1 }\end{array}$ & $\mathrm{CoO}$ & 1 & $22.9 \%$ & $\begin{array}{l}\text { (Mishra et } \\
\text { al., 2018) }\end{array}$ \\
\hline $\begin{array}{l}\text { Palm oil } \\
\text { mill } \\
\text { effluent }\end{array}$ & $\begin{array}{l}\text { Bacillus } \\
\text { anthracis } \\
\text { PUNAJAN } 1\end{array}$ & $\mathrm{NiO}+\mathrm{CoO}$ & $7.5+2.5$ & $37 \%$ & $\begin{array}{l}\text { (Mishra et } \\
\text { al., 2019) }\end{array}$ \\
\hline $\begin{array}{l}\text { Rice mill } \\
\text { wastewater }\end{array}$ & $\begin{array}{l}\text { Clostridium } \\
\text { beijerinckii } \\
\text { DSM } 791\end{array}$ & $\mathrm{NiO}$ & 1.5 & $\begin{array}{l}2.09 \text { times } \\
(109.1 \%)\end{array}$ & This work \\
\hline $\begin{array}{l}\text { Rice mill } \\
\text { wastewater }\end{array}$ & $\begin{array}{l}\text { Clostridium } \\
\text { beijerinckii } \\
\text { DSM } 791\end{array}$ & $\mathrm{CoO}$ & 1.5 & $90.4 \%$ & This work \\
\hline
\end{tabular}


962 Table 2 Kinetic parameters for biohydrogen production from RMWW using NiO NPs

\begin{tabular}{|c|c|c|c|c|c|c|c|c|}
\hline \multirow[b]{2}{*}{$\begin{array}{c}\text { NiO NPs } \\
\text { concentration } \\
(\mathbf{m g} / \mathrm{L})\end{array}$} & \multicolumn{4}{|c|}{ Gompertz model } & \multicolumn{4}{|c|}{ Modified logistic model } \\
\hline & $\begin{array}{c}\mathrm{MY}_{\mathbf{Y}} \\
(\mathrm{mL} \\
\left.\mathrm{H}_{2} / \mathrm{L}\right)\end{array}$ & $\begin{array}{c}M_{R} \\
(\mathbf{m L} \\
\left.\mathbf{H}_{2} / \mathbf{L ~ h}\right)\end{array}$ & $\begin{array}{c}\lambda \\
\text { (h) }\end{array}$ & $\mathbf{R}^{2}$ & $\begin{array}{c}\mathrm{MY}_{\mathbf{Y}} \\
(\mathrm{mL} \\
\left.\mathrm{H}_{2} / \mathrm{L}\right)\end{array}$ & 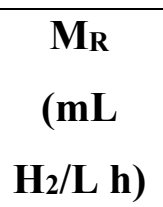 & $\begin{array}{c}\lambda \\
\text { (h) }\end{array}$ & $\mathbf{R}^{2}$ \\
\hline 0.0 & 101.23 & 5.50 & 1.31 & 0.9935 & 99.39 & 6.72 & 4.99 & 0.9815 \\
\hline 0.5 & 132.87 & 7.65 & 1.40 & 0.9929 & 130.57 & 10.25 & 4.79 & 0.9833 \\
\hline 1.0 & 157.88 & 10.41 & 1.27 & 0.9843 & 155.79 & 15.64 & 4.85 & 0.9771 \\
\hline 1.5 & 198.99 & 13.00 & 0.94 & 0.9678 & 196.01 & 20.08 & 3.15 & 0.9593 \\
\hline 2.0 & 182.03 & 12.50 & 1.23 & 0.977 & 179.83 & 19.18 & 3.29 & 0.9705 \\
\hline 2.5 & 160.96 & 10.56 & 1.15 & 0.9787 & 158.72 & 16.01 & 4.06 & 0.971 \\
\hline 3.0 & 118.99 & 6.29 & 1.29 & 0.9936 & 116.77 & 7.57 & 4.71 & 0.9813 \\
\hline
\end{tabular}

963

964

965

966

967

968

969

970

971

972

973

974

975

976

977

978

979

980

981

982 
983 Table 3 Kinetic parameters for biohydrogen production from RMWW using CoO NPs

\begin{tabular}{|c|c|c|c|c|c|c|c|c|}
\hline \multirow[b]{2}{*}{$\begin{array}{c}\text { CoO NPs } \\
\text { concentration } \\
(\mathrm{mg} / \mathrm{L})\end{array}$} & \multicolumn{4}{|c|}{ Gompertz model } & \multicolumn{4}{|c|}{ Modified logistic model } \\
\hline & $\begin{array}{c}\text { MY } \\
(\mathrm{mL} \\
\left.\mathbf{H}_{2} / \mathrm{L}\right)\end{array}$ & $\begin{array}{c}\mathrm{M}_{\mathrm{R}} \\
(\mathrm{mL} \\
\left.\mathrm{H}_{2} / \mathrm{L} \mathrm{h}\right)\end{array}$ & $\begin{array}{c}\lambda \\
\text { (h) }\end{array}$ & $\mathbf{R}^{2}$ & $\begin{array}{c}\mathrm{MY}_{\mathbf{Y}} \\
(\mathrm{mL} \\
\left.\mathrm{H}_{2} / \mathrm{L}\right)\end{array}$ & $\begin{array}{c}\mathrm{M}_{\mathrm{R}} \\
(\mathrm{mL} \\
\left.\mathrm{H}_{2} / \mathrm{L} \mathrm{h}\right)\end{array}$ & $\begin{array}{c}\lambda \\
\text { (h) }\end{array}$ & $\mathbf{R}^{2}$ \\
\hline 0.0 & 101.23 & 5.50 & 1.31 & 0.9935 & 99.39 & 6.72 & 4.99 & 0.9815 \\
\hline 0.5 & 119.72 & 6.22 & 1.38 & 0.9939 & 117.51 & 7.31 & 4.10 & 0.9818 \\
\hline 1.0 & 128.83 & 6.67 & 0.71 & 0.9828 & 125.84 & 8.82 & 3.44 & 0.9679 \\
\hline 1.5 & 181.11 & 10.31 & 0.49 & 0.9645 & 177.11 & 15.79 & 2.47 & 0.9515 \\
\hline 2.0 & 158.15 & 9.11 & 0.76 & 0.9737 & 154.97 & 13.55 & 3.08 & 0.962 \\
\hline 2.5 & 135.04 & 7.03 & 0.50 & 0.9759 & 131.71 & 9.83 & 3.29 & 0.9605 \\
\hline 3.0 & 110.62 & 5.46 & 1.33 & 0.9947 & 108.75 & 5.94 & 4.18 & 0.9814 \\
\hline
\end{tabular}

